\title{
$\checkmark$ Research Square \\ Climate velocities and lagged species elevational shifts in mountain ranges
}

Sheng-Feng Shen ( $\square$ shensf@sinica.edu.tw )

Academia Sinica https://orcid.org/0000-0002-0631-6343

\section{Wei-Ping Chan}

Harvard University

\section{Hung-Chi Kuo}

National Taiwan University

I-Ching Chen

National Cheng Kung University https://orcid.org/0000-0002-1909-7290

\section{Biological Sciences - Article}

Keywords: climate-endangered endemic species, mountain rangers

Posted Date: January 15th, 2021

DOl: https://doi.org/10.21203/rs.3.rs-108322/v1

License: (c) (i) This work is licensed under a Creative Commons Attribution 4.0 International License. Read Full License 
2

3 Climate velocities and lagged species elevational

4

5

6

7

8

9

10

11

12

13

14

15

16

17

19

20

21

22

\section{shifts in mountain ranges}

Authors: Wei-Ping Chan ${ }^{1,2,3}$, Hung-Chi Kuo ${ }^{4}$ I-Ching Chen $^{5 *}$ and

Sheng-Feng Shen ${ }^{1 *}$

Affiliations:

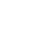

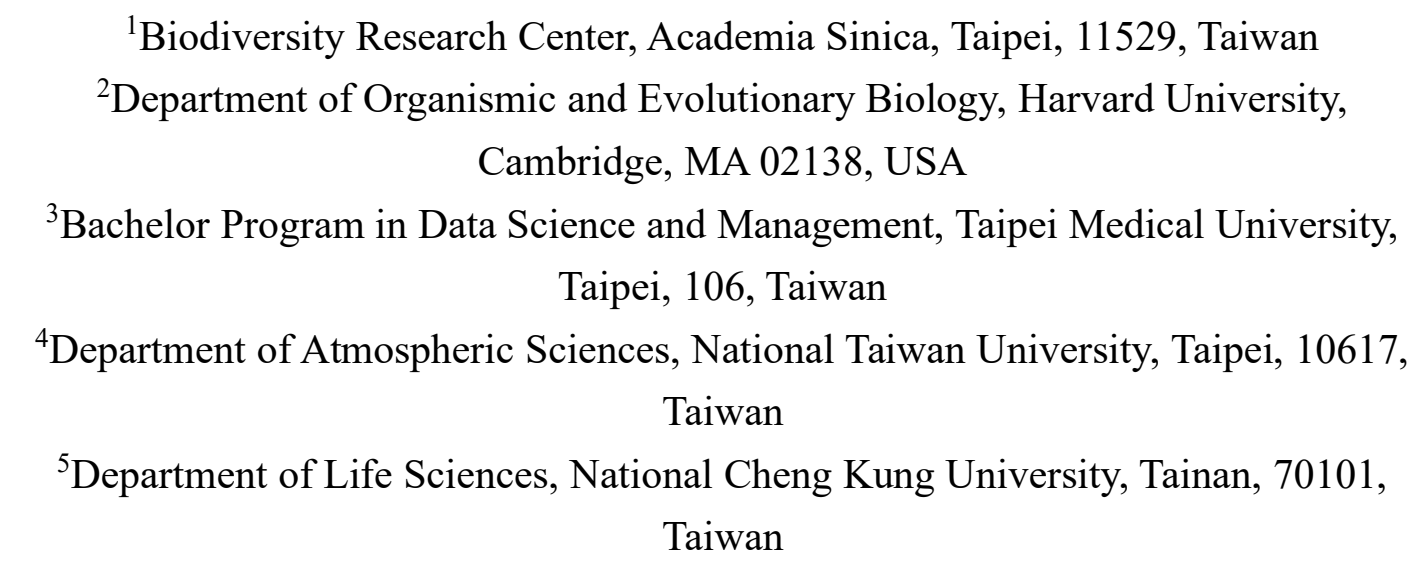




\section{Abstract}

Mountain ranges support concentrations of climate-endangered endemic species, and are potential refugia for species retreating from the lowlands under anthropogenic climate change. Predicting the outcome for biodiversity requires knowledge of whether species are shifting uphill at the same rate as temperature isotherms (i.e. whether they are successfully tracking the velocity of climatic changes) ${ }^{1}$. Here, we provide a global assessment of the velocity of climate change in mountain ranges: applying thermal dynamic theory, deriving moist adiabatic lapse rates (MALR) using local surface temperature and water vapor. MALR varied substantially around the world, from 3 to $9^{\circ} \mathrm{C}$ cooling per $\mathrm{km}$ elevation increase. Consider the rate of terrestrial surface warming from 1971 to 2015, 24 regions can be identified as exhibiting high velocities where the isotherms have shifted more than one standard deviation of the global mean value $\left(>8.45{\mathrm{~m} \mathrm{yr}^{-}}^{-}\right.$ 1). High velocities are typically found in relatively dry parts of the world, but also occur in wet regions with low lapse rates, such as in Northern Sumatra, Western Guiana Shield, Northern Andes, Costa Rica, Nepal, and Madagascar. Analysis of biodiversity data in relation to mountain-specific velocities revealed more cases of tracking between species and isotherms than previously suggested ${ }^{2}$ and more $^{2}$ likely occurred at lower climate velocity. Nevertheless, upslope migrations of montane species have generally been lagging behind climate velocity. Such lags could continue to effect change even if the climate were to stabilize immediately. Reducing emissions would be expected to minimize lags, as well as slow the velocities of warming and required responses everywhere. 
47 Mountainous regions represent $25 \%$ of the Earth's land surface but harbor disproportionately rich biodiversity, due in part to their steep climatic gradients and complex topography ${ }^{3,4}$. Thus, assessing the responses of montane biotas to anthropogenic climate change is particularly important for species conservation. Uphill movements of species towards cooler climates have been widely observed around the globe $e^{2,5-9}$ yet whether species are keeping pace with shifting climates remains unclear. The sparsity of meteorological stations in many mountain ranges ${ }^{10}$, combined with the climatic heterogeneity of complex topographies, make it difficult to determine the 'expected' responses of species if they were track climatic changes precisely. The simplest approach, which we adopt here, is to quantify the magnitude of climate isotherm shifts (i.e. the velocity of climate change) in each mountain range, and then estimate differences between observed range changes and isotherm shifts $^{1,9,11-15}$. We find that uphill movements are generally lagging behind climates and species have no opportunity to track climate effectively unless the velocity is low. The velocity of thermal isotherm shifts (in $\mathrm{km}$ of elevation $\mathrm{yr}^{-1}$ ) can be derived by dividing the temperature lapse rate (temperature decrease while ascending altitude, in ${ }^{\circ} \mathrm{C} \mathrm{km}^{-1}$ ) by the surface temperature change (in ${ }^{\circ} \mathrm{C} \mathrm{yr}^{-1}$ ). However, lapse rates (i.e. $5.5^{\circ} \mathrm{C} \mathrm{km}^{-1}$ in the tropics or $6.5^{\circ} \mathrm{C} \mathrm{km}^{-1}$ elsewhere) that are widely-applied have been inferred from limited ground observations ${ }^{2,8}$. Actual thermal lapse rates can vary substantially in different regions and this has not been explicitly considered in ecological research. Temperature lapse rate is the decrease of temperature with increasing altitude. The pressure of the air decreases when a parcel of air molecules rises and expands with negligible heat transfer conduction and radiation from outside, which costs internal energy, cooling the parcel. The consequent rate of cooling is referred as adiabatic lapse rate ("adiabatic" meaning that no external source of energy 
72 was involved, and the value often used is $9.8^{\circ} \mathrm{C} \mathrm{km}^{-1}$ ). However, if the air condenses

73 moisture as it cools, it gains some heat of condensation, which slows the rate of

74 cooling. Thus, realized or "moist adiabatic" lapse rates (MALR) are often lower (e.g.

$756.5^{\circ} \mathrm{C} \mathrm{km}^{-1}$ ) than the adiabatic lapse rate. As a consequence, temperature lapse rates

76 are determined by water vapor changes and latent heat release, which are linked to

77 surface temperature, elevation and moisture content in the region of interest ${ }^{16}$.

78 Importantly, the limited data available indicates that temperature lapse rates

79 differ between regions and seasons $s^{16,17}$. For example, lapse rates range from $4 \cdot 1^{\circ} \mathrm{C}$

$80 \mathrm{~km}^{-1}$ to $6.8^{\circ} \mathrm{C} \mathrm{km}^{-1}$ for different times and seasons along the slopes of the central

81 Himalayas $^{18}$. In the Washington Cascades mountains in North America, the values of 82 lapse rates vary from $2.5 \mathrm{~km}^{-1}$ to $7.5^{\circ} \mathrm{C} \mathrm{km}^{-1}$ in late summer and spring ${ }^{19}$.

83 Nonetheless, the mechanisms underlying temperature lapse rate are well established

84 in thermodynamic theory, with MALR being a function of local temperature and

85 vapor pressure ${ }^{20}$. Here, we use this knowledge to assess the velocity of mountain

86 climate changes on a global scale, and then evaluate whether species are keeping pace

87 with shifting isotherms. Mountain areas were represented by grids with $0.5^{\circ}$

88 resolution of mean elevation above $1,000 \mathrm{~m}^{21}$ (Figs. 1,2). The velocity is represented

89 by the vertical isotherm shifts (i.e. how far an isothermal line rises from the surface),

90 calculated by dividing the rate of warming in each mountain grid by its MALR,

91 derived from terrain-surface conditions. We estimate MALR (usually noted as $\Gamma_{w}$ ) as:

$$
\Gamma_{w}=g \frac{1+\frac{H_{v} \gamma}{R_{s d} T}}{C_{p d}+\frac{H_{v}^{2} \gamma \epsilon}{R_{s d} T^{2}}}
$$

93 where $\gamma$ is the mixing ratio of the mass of water vapor per unit mass of dry air, which

94 is also influenced by air pressure; T represents the air temperature (other parameters

95 are constants; see Methods). We use mean annual temperature and water vapor 
pressure at terrain surface from 2011 to 2015 from CRU TS 3.24 to calculate MALR and consider the rate of warming from 1971 to 2015 for each mountain grid. The MALR formula predicts that higher surface temperature or water vapor leads to curvilinear decreases in MALR (Fig. 1a). Given the widely varied temperature and water vapor differences between mountain grids (Fig. 1 b,c), our estimates show that temperature lapse rates of global mountains vary from 3 to $9^{\circ} \mathrm{C} \mathrm{km}^{-1}$ (Fig 1d).

Given these MALR estimates and the rates of surface temperature change (Fig. 2 a,b), the climate velocities in global mountains vary considerably from $-16.67 \mathrm{~m} \mathrm{yr}^{-1}$ (Saltillo, Mexico) to $+16.80 \mathrm{~m} \mathrm{yr}^{-1}$ (Mashhad, Iran), with global average elevational isotherm increases of $+5.42 \pm 0.03 \mathrm{~m} \mathrm{yr}^{-1}$ in mountain ranges (Fig. 2c; Extended Data Fig. 1). We identify high climate-velocity mountains where the isotherms have shifted more than one standard deviation of the global mean value (higher than $8.45 \mathrm{~m} \mathrm{yr}^{-1}$ ) (Fig. 2d). Defined in this way, about $16 \%$ of mountainous areas are exposed to high climate velocity and many are well-recognized biodiversity hotspots, such as Northern Sumatra, Hengduan, Nepal, Southern Ghats, Madagascar, Mediterranean basin, Northern Sahara, Brazilian Highlands, Northern Andes, Costa Rica, and Western America and Mexico (Supplementary Table 1). Other high velocity mountains may also be of concern, including most of the Middle East mountains (which includes endemics) and central Asia, Siberia, and the Alaska-Yukon region (Supplementary Table 1). The approach delineates that high climate velocity can be due to high rates of temperature warming or to low lapse rates. It is intuitive that higher warming rate results in high climate velocity (Extended Data Fig. 2a) and this is often observed in drier regions with low mean annual precipitation (MAP), possibly due to the limited heat capacity of arid regions ${ }^{22-24}$ (Supplementary Table 1). Yet, high climate velocities are also observed in mountain ranges that have relatively modest levels of warming but low lapse rates, which can occur at areas with high water 
vapour pressure and/or high surface temperatures (Extended Data Fig. 2b, and Supplementary Table 1). Many of these areas coincide with wet climates (high MAP), such as in Northern Sumatra, Western Guiana Shield, Northern Andes Mts, Costa Rica, and Nepal (Extended Data Fig. 2b, and Supplementary Table 1). Mountain climate velocities emerge from the interactions of lapse rates and water vapor pressure, interacting with mountain topographies and levels of regional warming. We also applied our framework to mountains on islands that harbor a high proportion of endemic species and provide refuges for shifting species otherwise constrained by the ocean ${ }^{25,26}$. We define islands as landmasses that are smaller than Australia and surrounded by water ${ }^{21}$. We examined the velocity of climate change in island mountains globally (only 14 islands have mountain grid cells higher than 1,000 $\mathrm{m}$, based on our dataset) and found a mean shift of $3.35 \mathrm{~m} \mathrm{yr}^{-1}$, which was lower than the global average (5.42 $\left.\mathrm{m} \mathrm{yr}^{-1}\right)$. Two island regions - Madagascar and Japan — were found to have high climate velocity $\left(>8.45 \mathrm{~m} \mathrm{yr}^{-1}\right)$ (Fig. 3a-c). In Japan, high climate velocity is mainly caused by the surface temperature warming (Fig. 2b,

Supplementary Table 1) but, interestingly, Madagascar is not adjacent to ocean with particularly high levels sea surface warming ${ }^{27}$ (Fig. 2b, Supplementary Table 1); for Madagascar, high water vapour levels generate a low lapse rate, and hence the high climate velocity (Supplementary Table 1). High climate velocity in these islands may lead to considerable biodiversity loss, which illustrates the importance of developing climate adaptation strategies ${ }^{28}$.

Growing evidence shows that the rate of warming varies with elevation ${ }^{10}$. The sparse long-term meteorological stations in mountain areas have hampered a global test of elevation dependent warming ${ }^{29}$. Our study reveals a complex pattern of elevation-dependent climate velocity (Fig. 3d-f and Extended Data Fig. 3). 
Accelerated climate velocity with elevation can be observed in the low latitudes ( $c a$. $10^{\circ} \mathrm{N} / \mathrm{S}$ ) but high velocity occurs mostly at low elevation near the equator and at 30$40^{\circ} \mathrm{N}, 60-70^{\circ} \mathrm{N}$ and $20-30^{\circ} \mathrm{S}$, in line with the projections of the IPCC Fifth Assessment Report ${ }^{30}$. These complex patterns support the call for greater undestanding of the patterns and causes of elevation-dependent warming ${ }^{10}$.

Since factors such as whether the slopes face the sun may have a major impact on the mountain climate ${ }^{31}$, we further explored how the topography of the mountains, including the aspect and orientation of the mountains, affects climate velocity. We investigate how mountain climate velocities differ among different aspects and orientations. Apart from commonly known North-South and East-West orientations, we further defined two categories: mountains facing east and equator are called EastEquator mountains; facing west and equator, West-Equator mountains (Extended Data Fig. 4a). We found that climate velocities are higher in East-facing and West-facing slopes than other slopes $\left(\chi^{2}=11.06, p=0.011\right.$, d.f. $\left.=3\right)($ Extended Data Fig. $4 b)$, which are associated with the higher water vapor in these aspects of slopes than the others $\left(\chi^{2}=687.76, p<0.001\right.$, d.f. $\left.=3\right)($ Extended Data Fig. $4 c)$ even though the warming rates were lower than the other slopes $\left(\chi^{2}=267.62, \mathrm{p}<0.001\right.$, d.f. $\left.=3\right)$ (Extended Data Fig. 4d). Regarding the orientation, climate velocities are significantly higher in East-Equator (orientations illustrated in Extended Data Fig. 4) and North-South mountains than mountain ranges of other orientations $\left(\chi^{2}=765.72\right.$, $\mathrm{p}<0.001$, d.f. $=3)($ Extended Data Fig. 4 e). Water vapor values are significantly higher in East-Equator mountains $\left(\chi^{2}=521.72, p<0.001\right.$, d.f. $=3$, Extended Data Fig. 4f) but surface temperature changes are significantly higher in North-South mountains, compared to East-West and West-Equator mountains (E-W: $\mathrm{z}=-9.05, \mathrm{p}<0.001$; WEquator: $\mathrm{z}=-7.98, \mathrm{p}<0.001$ ) (Extended Data Fig. 4g). This observation is generally 
consistent in mountain orientations of different aspects (Extended Data Fig. 5).

Our study provides estimates of the rates of elevational shifts required by species and whether they tracked (kept pace with) temperature changes precisely or lagged behind. We compared these rate estimates with observed elevational shifts in montane species, taken from peer-reviewed articles reporting multi-species elevational redistributions (Supplementary Table 2). The global variation in predicted elevation shifts in different mountain ranges shows that rates of expected species uplifts are much lower (e.g. in Italy and France) than predicted in the original paper using widely applied empirical values (range from $5.5^{\circ} \mathrm{C} \mathrm{km}^{-1}$ to $6.5^{\circ} \mathrm{C} \mathrm{km}^{-1}$ ) or a globallyaveraged lapse rate of $5.5^{\circ} \mathrm{C} \mathrm{km}^{-1}$ (Extended Data Fig. 6), and this may partially explain previous findings that mountain species appeared to be generally lagging behind climate changes ${ }^{2}$. To assess the probability of species tracking climate velocity, considering each taxon at each region as one data-point, we conducted bootstrapping to control the sample size effect and compare the probability of tracking in relation to climate velocity (Fig. 4a). Each dataset was subsampled and the mean shift was compared with its corresponding climate velocity, using Wilcoxon signedrank test at significance level of 0.05 . If the shifts of species are not significantly different from the climate velocity, we consider the species successfully track the climate velocity. We repeated the procedure for 1000 times $(i=1000)$ and used the percentage of numbers that are not significantly different from the climate velocity as the probability of tracking successfully (Fig. 4b-c; significant levels at $p=0.01$ and 0.001 were shown in Fig.4d \& 4e). The probability of species tracking thus represents the variation within each data point and provided better assessment than comparing only the mean values of shifts, i.e. data points that are closer to the 1:1 diagnose line are not necessarily tracking better. Plotting the probability of species tracking demonstrated that mountain species are generally lagging behind the climate 
velocities with exceptions more likely occurring at lower velocities (Fig. 4b, Extended Data Fig. 7).

By applying the well-established thermodynamic theory of MALR, we provide a global assessment of climate velocity in mountain ranges and identify 24 major regions with high climate velocities. In addition to dry regions with increasing surface temperatures ${ }^{32,33}$, we identify mountains where high water vapor causes high climate velocity. Based on the newly calculated climate velocity, we also evaluate the probability of species tracking climate velocity in global mountains. Many ecological studies rely on average lapse rates collected by the sounding balloon method, tying a thermometer on a balloon in order to collect the temperature profile vertically, to estimate isothermal line shifts in mountain regions. The more accurate estimations of climate velocity provide potential explanations for the largely lagged upslope migrations previously documented in many species. Nevertheless, the biological impacts of climate change have largely been studied in North America and Europe $^{34,35}$, where the velocities of mountain climate change are relatively slower than most other parts of the world. We still have a limited understanding of whether species generally move uphill more slowly than the shift of isothermal lines ${ }^{9}$ and, if they do move more slowly, what the ecological impacts of climate change are for these lagging species.

Our estimation of global temperature lapse rates, based on the MALR formula considering the latent heat release and water vapor changes, provides a heuristic understanding of climate velocity in global mountains. However, many other mechanisms, such snow albedo, radiative flux changes, surface heat loss and aerosols, also influence the energy balance regimes, making a direct estimate of climate conditions and climate change in extremely difficult in mountain regions ${ }^{10}$. Nevertheless, since mountains may effectively provide shelters for many rare and 
226 endangered species, our study helps identify vulnerable regions with high climate

227 velocity, which we suggest are priority regions for conservation. Given this

228 vulnerability, extensive monitoring networks for both mountain climate and biological

229 impacts are urgently needed. 
232 The climatic data, including mean annual temperature and water vapor pressure, and

233 the corresponding global digital elevation model were derived from the gridded CRU 234 TS3.24 database $\left(0.5^{\circ}\right.$ resolution $)$, which we averaged over every 5 years. Both mean 235 annual temperature and water vapor pressure were derived from local weather stations 236 and subsequently averaged across coarse spatial extent to obtain the final values ${ }^{24}$.

237 MALR at each grid was generated by the MALR formula:

$$
\Gamma_{w}=g \frac{1+\frac{H_{v} \gamma}{R_{s d} T}}{C_{p d}+\frac{H_{v}^{2} \gamma \epsilon}{R_{s d} T^{2}}}
$$

239 where $\Gamma_{w}$ is the moist adiabatic lapse rate $(\mathrm{K} / \mathrm{m}), g$ denotes the Earth's gravitational acceleration $\left(9.8076 \mathrm{~m} / \mathrm{s}^{2}\right), H_{v}$ denotes the heat of water vaporization $(2,501,000$ $\mathrm{J} / \mathrm{kg}), R_{s d}$ denotes the specific gas constant of dry air $\left(287 \mathrm{~J} \mathrm{~kg}^{-1} \mathrm{~K}^{-1}\right), \epsilon$ denotes the dimensionless ratio of the specific gas constant of dry air to the specific gas constant for water vapour $(0.622), C_{p d}$ denotes the specific heat of dry air at constant pressure $\left(1,005 \mathrm{~J} \mathrm{~kg}^{-1} \mathrm{~K}^{-1}\right)$, and $T$ denotes the air temperature $(\mathrm{K}) . \gamma$ is the mixing ratio of the mass of water vapor to the mass of dry air:

$$
\gamma=\epsilon e /(p-e)
$$

247 where $e$ represents the water vapor pressure of the air and $p$ represents the pressure 248 of the air. Here, $p$ was derived from the Barometric formula:

$$
p=p_{b} \times \exp \left[\frac{-g \times M \times h}{R \times T}\right]
$$

250 where $p_{b}$ denotes the static pressure (101,325.00 pascals), $M$ denotes the molar 251 mass of Earth's air $(0.0289644 \mathrm{~kg} / \mathrm{mol}), R$ denotes the universal gas constant for air 252 (8.31432 $\left.\mathrm{N} \mathrm{m} \mathrm{mol}^{-1} \mathrm{~K}^{-1}\right), h$ denotes the height above sea level (meters), and $T$ 253 denotes the standard temperature $(\mathrm{K})$. 
254 The preprocessing of climatic variables (from monthly data to annual data) and the 255 calculation of basic climate velocity and climate velocity was computed by pySpark.

256 Islands are defined as landmasses that are smaller than Australia and surrounded by

257 water ${ }^{21}$. Here, the input dataset is not the digital elevation model (DEM) from CRU

258 but from SRTM, which is more conservative on defining terrestrial area (smaller

259 terrestrial regions), so it is better for island detection (the islands near shores are not

260 connected to continents). Greenland is not included as it is not surrounded by the

261 ocean in the dataset. These analyses were run in Wolfram Mathematica 9. Though we

262 only present the results when the anthropogenic warming accelerated (Extended Data

263 Fig. 8) in our main text, the results from 1901 to 2015 can be found in Supplementary

264 Fig. $1 \& 2$.

265

266 Topographical analysis and corresponding data sources

267 The surface aspect of each pixel was calculated by using the Surface Aspect Tool in 268 ArcGIS Pro (the license of 3D analyst is required), and the input digital elevation 269 model (DEM) is from CRU in order to match the climatic data. Two characters

270 (elongation and orientation) were calculated for each mountain ranges previously

271 defined in the literature ${ }^{36}$ in Wolfram Mathematica 9. Elongation is defined as 1-

272 (smallest axis of the best-fit ellipse / largest axis of the best-fit ellipse), and

273 orientation is computed as the angle between the largest axis and the horizontal axis.

274 The orientation of only those mountains having elongation value greater than 0.5 were

275 further analyzed. To provide a better alignment with the definition of global

276 mountains described in the main text, we then analyzed climatic data from elevations

277 higher than 1,000 m (a.s.1.) within these 'expert-identified' mountains. For the clarity,

278 we summarized the results based on categories of surface aspects and orientations of

279 mountains (Extended Data Fig. 4a). Kruskal-Wallis test (non-parametric) was applied 
to statistically quantify the differences across different aspects and orientations of mountains. A Wilcoxon signed-rank test was then applied in paired-dataset comparisons as a post Hoc analysis.

\section{Biological datasets}

We adapted published studies providing range- or boundary-shift information based on an exhaustive literature review (Supplementary Table 2). Generally, literature was collected based on Chen et al. 2011 and updated to 2017. Investigations of different taxa within the same region were considered as different records (e.g., $\left.{ }^{37}\right)$. Certain records collected during this process were subsequently discarded from the dataset when either: (1) the values returned two different studies in the same region were enormously different, specifically exceeding a ratio of 5 (e.g., in Spain [Sierra Nevada $]^{38}$, the number of samples in two investigating periods were 1,168 V.S. 29,174); (2) the information provided in a large-scale (exceed 5 x 5 degree on the map) research was insufficient, so we could not divide the records into geographical regions (e.g., ${ }^{39}$ ). Along with the raw datasets we used in our analysis, statistically summarized information for all literature is also provided. The standard error was not provided for studies with (1) only one record in a region or (2) insufficient information from the original paper.

\section{Corresponding climate velocity to the biological data}

To pair biological records with the climate velocity derived from MALR, climate velocities were assigned or statistically summarized based on the following criteria: (1) if the spatial scale of a research was less than $1 \times 1$ degree (i.e. distributed within a grid), the climate velocity at the same corresponding grid was used (eg. $\left.{ }^{40}\right)$; (2) if the scale of a study exceeded 1 x 1 degree (i.e., distributed on multiple grids), the regional 
climate velocity was statistically calculated (provided as mean, variance, and sample size; e.g. ${ }^{41}$ ); (3) if the study region exceeds $5 \times 5$ degrees, the biological records were grouped into different regions (e.g. ${ }^{8}$ ), and the climate velocity of each region was derived based on criteria 1 and 2; (4) for studies encompassing multiple regions and periods, the corresponding spatiotemporal information was used in order to derive the most accurate climate velocity (eg., ${ }^{42}$ ); (5) if a study investigated the same region multiple times in different temporal periods, the same geographical information was used (e.g. $\left.{ }^{43}\right)$.

The probability of species tracking climate velocity — comparing biological data and climate velocity

317 In order to statistically compare the biological data with corresponding climate velocity, we calculated the probability of species tracking climate velocity after

319 bootstrapping the data to meet a relatively constant sample size across regions and taxa. Some studies did provide detailed raw data (Supplementary Table 2), but for

321 those only reporting statistical results — such as mean and variance/standard

322 deviation/error (Extended Data Fig. 9) - we applied different probability distribution

323 functions, normal distribution as well as non-normal distributions (log-normal and

324 Student-t distribution), in our statistical analysis according to the statistical

325 characteristics (mean and standard deviation/error) provided in the original reports.

326 The nature of non-normally-distributed frequency in our dataset (Supplementary Fig.

327 3) was taken cared here, and the final probability reported was averaged from all three 328 approaches with different probabilities.

329 The probability of species tracking climate velocity was then calculated as follows:

330 First of all, we used the bootstrap technique to subsample the dataset to control the 331 inconsistencies induced by having different sample sizes across studies. For each 
taxon in each region, we set the sample size to $n$ and drew $n$ records ( $n$ in Fig. 4a). If the total number of records for that taxon in that region is smaller than $n$, all records were used. For those only reporting statistical results (21 out of 47), we applied different probability functions to generate the drawn value as described in the previous paragraph. The drawn biological data were then compared to the corresponding climatic velocity using the non-parametric method-Wilcoxon signedrank test—because many datasets did not satisfy the normal distributed assumption (Supplementary Fig. 3). This procedure (draw and comparison) was then iterated 1,000 times ( $i$ in Fig. 4a), and we calculated the number of iterations at which the biological data showed no significant difference to the corresponding climate velocity (i.e., did not meet the significant level, 0.05; $p$ in Fig. 4 which implies the ability of tracking climate change; the lower $p$, the higher ability) and divided it by the total number of iterations $(1,000 ; i$ in Fig. $4 a)$; the result was the probability of species tracking climate velocity. A logistic-type (probit) function was then applied to estimate the probability curve. We also ran a sensitivity analysis by setting different values for $n(30,40,50,60,70,80,90$, and 100), and the results indicated that $n$ does not influence the probability of species tracking climate velocity (Supplementary Table 3), so we decided to set $n=30$ to fairly address the small-sample-size research. The data processing and statistical analysis in this section were done in R.

\section{Probability of species tracking using different lapse rate calculations}

The straightforward thought to test how better climate velocity derived from MALR (with the consideration of water vapor) is tracked by species should be: applying regression for water vapor and the residual that derived from the regression of biological records and local constant lapse rate (which does not consider water vapor). However, given that the relation between water vapor and lapse rate is non-linear 
358 (MALR formula and Fig. 1a), the analysis based on the concept of regression should 359 not work. In order to bridge the method, which is more familiar to readers, to our 360 formal analysis (which is going to be described later), we firstly provide a set of 361 intuitive but potentially biased histograms to show the different explanation powers 362 among different lapse rate calculations (Extended Data Fig. 10a). The residual 363 between mean observed shifting rate and the mean climate velocity derived from 364 different lapse rate calculations for a taxon are shown. We can still find that the 365 residual histogram of MALR is more normally distributed than that of others (i.e. it 366 explains biological dataset better than others), yet please note that this method 367 neglects the variance of different records of a taxon. Consequently, in order to 368 formally compare different lapse rate calculations, the method with probability scope 369 and subsampling is applied. Based on the results generated from the previous section, 370 we further calculated the averaged probability of species tracking climate velocity 371 (the concept behind this analysis is quite similar to the survival analysis ${ }^{44}$ ). We sorted 372 the data by ascending climate velocities and then calculated the cumulated probability 373 for each record before dividing it by the cumulated number of records. For example, 374 there are four records (format: probability of species tracking climate velocity, climate 375 velocity): $(0.98,0.2),(0.90,0.4),(0.75,0.6),(0.6,0.7)$. The averaged probability 376 under a certain climate velocity would then be: $(0.98,0.2),(0.94,0.4),(0.88,0.6)$, $377(0.81,0.7) .0 .94$ is from $(0.98+0.90) / 2 ; 0.88$ is from $(0.98+0.90+0.75) / 3 ; 0.81$ is from $378(0.98+0.90+0.75+0.60) / 4$. This result can be directly compared to the ultimate impacts 379 of lapse rates derived from different methods (local constant lapse rate, constant lapse 380 rate, and MALR) on the probability of species tracking climate velocity (Extended 381 Data Fig. 10b). The analysis was done in R. 


\section{Main References}

3841 Loarie, S. R. et al. The velocity of climate change. Nature 462, 1052-U1111, 385 doi:10.1038/nature08649 (2009).

3862 Chen, I.-C., Hill, J. K., Ohlemüller, R., Roy, D. B. \& Thomas, C. D. Rapid range 387 shifts of species associated with high levels of climate warming. Science 333, 388 1024-1026 (2011).

3893 Rahbek, C. et al. Building mountain biodiversity: Geological and evolutionary 390 processes. Science 365, 1114-1119, doi:10.1126/science.aax0151 (2019).

3914 Rahbek, C. et al. Humboldt's enigma: What causes global patterns of 392 mountain biodiversity? Science 365, 1108-1113 (2019).

3935 Lenoir, J. \& Svenning, J. C. Climate-related range shifts-a global 394 395 396 397 398 399 400 401 402 multidimensional synthesis and new research directions. Ecography 38, 15-28 (2015).

403

404

405

6 Morueta-Holme, N. et al. Strong upslope shifts in Chimborazo's vegetation over two centuries since Humboldt. P Natl Acad Sci USA 112, 12741-12745 (2015).

7 Freeman, B. G., Lee-Yaw, J. A., Sunday, J. M. \& Hargreaves, A. L. Expanding, 406 407 shifting and shrinking: The impact of global warming on species' elevational distributions. Global Ecol Biogeogr 27, 1268-1276 (2018).

408 Freeman, B. G. \& Freeman, A. M. C. Rapid upslope shifts in New Guinean birds illustrate strong distributional responses of tropical montane species to global warming. P Natl Acad Sci USA 111, 4490-4494 (2014). Lenoir, J. et al. Species better track climate warming in the oceans than on land. Nature Ecology \& Evolution, 1-16 (2020). Pepin, N. et al. Elevation-dependent warming in mountain regions of the world. Nat Clim Change 5, 424-430, doi:10.1038/Nclimate2563 (2015). Brito-Morales, I. et al. Climate velocity can inform conservation in a warming world. Trends in ecology \& evolution 33, 441-457 (2018).

Burrows, M. T. et al. The Pace of Shifting Climate in Marine and Terrestrial Ecosystems. Science 334, 652-655, doi:10.1126/science.1210288 (2011).

3 Pinsky, M. L., Worm, B., Fogarty, M. J., Sarmiento, J. L. \& Levin, S. A. Marine Taxa Track Local Climate Velocities. Science 341, 1239-1242, doi:10.1126/science.1239352 (2013).

Poloczanska, E. S. et al. Global imprint of climate change on marine life. Nat Clim Change 3, 919-925, doi:10.1038/Nclimate1958 (2013).

15 Schloss, C. A., Nunez, T. A. \& Lawler, J. J. Dispersal will limit ability of mammals to track climate change in the Western Hemisphere. P Natl Acad Sci USA 109, 8606-8611, doi:10.1073/pnas.1116791109 (2012). 

Parameterization. J Atmos Sci 36, 415-423, doi:Doi 10.1175/15200469(1979)036<0415:Alrrat>2.0.Co;2 (1979).

42417 Meyer, H. W. Lapse rates and other variables applied to estimating paleoaltitudes from fossil floras. Palaeogeography, Palaeoclimatology, Palaeoecology 99, 71-99 (1992).

Kattel, D. et al. Temperature lapse rate in complex mountain terrain on the southern slope of the central Himalayas. Theoretical and Applied Climatology 113, 671-682 (2013). Minder, J. R., Mote, P. W. \& Lundquist, J. D. Surface temperature lapse rates over complex terrain: Lessons from the Cascade Mountains. Journal of Geophysical Research: Atmospheres 115 (2010). Holton, J. R. \& Hakim, G. J. An introduction to dynamic meteorology. Vol. 88 (Academic press, 2012). Kreft, H., Jetz, W., Mutke, J., Kier, G. \& Barthlott, W. Global diversity of island floras from a macroecological perspective. Ecol Lett 11, 116-127 (2008). Huang, J., Guan, X. \& Ji, F. Enhanced cold-season warming in semi-arid regions. Atmos Chem Phys 12, 5391-5398, doi:10.5194/acp-12-5391-2012 (2012).

23 Huang, J., Yu, H., Guan, X., Wang, G. \& Guo, R. Accelerated dryland expansion under climate change. Nat Clim Change (2015).

450

27 Kenyon, J. \& Hegerl, G. C. Influence of modes of climate variability on global

453 temperature extremes. J Climate 21, 3872-3889, doi:Doi 10.1175/2008jcli2125.1 (2008). 
29 Rangwala, I. \& Miller, J. R. Climate change in mountains: a review of

460

461

462

463

464

465

466

467

468

469

470

471

472

473

474

475

476

477

$478 \quad 36$

479

480

481

482

483

484

485

486

487

488

489

490

491

492

493

494

495

496 elevation-dependent warming and its possible causes. Climatic Change 114, 527-547 (2012).

30 Collins, M. et al. in Climate Change 2013-The Physical Science Basis: Contribution of Working Group I to the Fifth Assessment Report of the Intergovernmental Panel on Climate Change 1029-1136 (Cambridge University Press, 2013).

31 Waring, R. H. \& Running, S. W. Forest ecosystems: analysis at multiple scales. (Elsevier, 2010).

32 Lioubimtseva, E. \& Henebry, G. M. Climate and environmental change in arid Central Asia: Impacts, vulnerability, and adaptations. J Arid Environ 73, 963977, doi:DOI 10.1016/j.jaridenv.2009.04.022 (2009).

33 Sorg, A., Bolch, T., Stoffel, M., Solomina, O. \& Beniston, M. Climate change impacts on glaciers and runoff in Tien Shan (Central Asia). Nat Clim Change 2, 725-731, doi:Doi 10.1038/Nclimate1592 (2012).

34 Pecl, G. T. et al. Biodiversity redistribution under climate change: Impacts on ecosystems and human well-being. Science 355, eaai9214 (2017).

35 Pacifici, M. et al. Assessing species vulnerability to climate change. Nat Clim Change 5, 215 (2015).

36 Elsen, P. R. \& Tingley, M. W. Global mountain topography and the fate of montane species under climate change. Nat Clim Change 5, 772 (2015).

37 Hickling, R., Roy, D. B., Hill, J. K., Fox, R. \& Thomas, C. D. The distributions of a wide range of taxonomic groups are expanding polewards. Global Change Biol 12, 450-455 (2006).

38 Menendez, R., Gonzalez-Megias, A., Jay-Robert, P. \& Marquez-Ferrando, R. Climate change and elevational range shifts: evidence from dung beetles in two European mountain ranges. Global Ecol Biogeogr 23, 646-657 (2014).

39 Pauli, H. et al. Recent Plant Diversity Changes on Europe's Mountain Summits. Science 336, 353-355 (2012).

40 Reif, J. \& Flousek, J. The role of species' ecological traits in climatically driven altitudinal range shifts of central European birds. Oikos 121, 1053-1060 (2012).

41 Holzinger, B., Hulber, K., Camenisch, M. \& Grabherr, G. Changes in plant species richness over the last century in the eastern Swiss Alps: elevational gradient, bedrock effects and migration rates. Plant Ecol 195, 179-196 (2008).

42 Tingley, M. W., Koo, M. S., Moritz, C., Rush, A. C. \& Beissinger, S. R. The push and pull of climate change causes heterogeneous shifts in avian elevational ranges. Global Change Biol 18, 3279-3290 (2012). 
Jump, A. S., Huang, T. J. \& Chou, C. H. Rapid altitudinal migration of mountain plants in Taiwan and its implications for high altitude biodiversity. Ecography 35, 204-210 (2012).

$50044 \quad$ Pollock, K. H., Winterstein, S. R., Bunck, C. M. \& Curtis, P. D. Survival analysis in telemetry studies: the staggered entry design. The Journal of Wildlife

503 J. Biodiversity hotspots for conservation priorities. Nature 403, 853-858 (2000).

506

46 Bergamini, A., Ungricht, S. \& Hofmann, H. An elevational shift of cryophilous

507 bryophytes in the last century - an effect of climate warming? Divers Distrib 15, 871-879 (2009). ranges associated with climate change. Ecol Lett 8, 1138-1146, doi:10.1111/j.1461-0248.2005.00824.x (2005). from warming and upslope displacement: a preliminary appraisal for the highest massif in Madagascar. Global Change Biol 14, 1703-1720 (2008). Archaux, F. Breeding upwards when climate is becoming warmer: no bird response in the French Alps. Ibis 146, 138-144 (2004). Popy, S., Bordignon, L. \& Prodon, R. A weak upward elevational shift in the distributions of breeding birds in the Italian Alps. J Biogeogr 37, 57-67 (2010). Zuckerberg, B., Woods, A. M. \& Porter, W. F. Poleward shifts in breeding bird distributions in New York State. Global Change Biol 15, 1866-1883 (2009). Moritz, C. et al. Impact of a century of climate change on small-mammal communities in Yosemite National Park, USA. Science 322, 261-264, doi:10.1126/science.1163428 (2008).

532 warming trend in the Alps. Basic Appl Ecol 9, 100-107 (2008). climate change. P Natl Acad Sci USA 105, 11823-11826 (2008).

55 Lenoir, J., Gegout, J. C., Marquet, P. A., de Ruffray, P. \& Brisse, H. A significant upward shift in plant species optimum elevation during the 20th century. Science 320, 1768-1771 (2008).

6 le Roux, P. C. \& McGeoch, M. A. Rapid range expansion and community reorganization in response to warming. Global Change Biol 14, 2950-2962 (2008). 
distribution of butterflies in the Czech Republic: effects of changing climate detected on a regional scale. Global Ecol Biogeogr 12, 403-410 (2003).

$53758 \quad$ Franco, A. M. A. et al. Impacts of climate warming and habitat loss on extinctions at species' low-latitude range boundaries. Global Change Biol 12,

$54059 \quad$ Feeley, K. J. et al. Upslope migration of Andean trees. J Biogeogr 38, 783-791

541 (2011).

54260 Forero-Medina, G., Joppa, L. \& Pimm, S. L. Constraints to Species' Elevational 543 Range Shifts as Climate Changes. Conserv Biol 25, 163-171 (2011).

54461 Felde, V. A., Kapfer, J. \& Grytnes, J. A. Upward shift in elevational plant species 545 ranges in Sikkilsdalen, central Norway. Ecography 35, 922-932 (2012).

54662 Telwala, Y., Brook, B. W., Manish, K. \& Pandit, M. K. Climate-Induced

547 Elevational Range Shifts and Increase in Plant Species Richness in a Himalayan 548

549

63 Auer, S. K. \& King, D. I. Ecological and life-history traits explain recent

550

551

552

64 Wolf, A., Zimmerman, N. B., Anderegg, W. R. L., Busby, P. E. \& Christensen, J.

553

554

555 Altitudinal shifts of the native and introduced flora of California in the context

556 of 20th-century warming. Global Ecol Biogeogr 25, 418-429 (2016).

558

559

\section{Data availability}

560 Source datasets are provided at

561 https://datadryad.org/stash/share/cvQWOmBfKEki5GoHVkl-

562 7yeOgRvAwkoEQquwEO13wB4

563

564 Code availability

565 The code used for analysis can be found at

566 https://datadryad.org/stash/share/cvQWOmBfKEki5GoHVkl-

567 7yeOgRvAwkoEQquwEO13wB4 


\section{Acknowledgements}

569 We thank Y.-S. Chang and T.-C. Hiseh for helping process the topographical dataset;

570 C.-H. Chen for providing statistical suggestion at the early stage of this study; C.

571 Tomas, R. Childers, and C.-N. Chou for their comments on the early version of the

572 manuscript. This work is funded by Ministry of Science and Technology, Taiwan

573 (103-2621-B-001 -003 -MY3 and 101-2313-B-001 -008-MY3 to S.-F. S.) and

574 Academia Sinica (AS-SS-106-05 and AS-IA-106-L01 to S.-F.S.).

575

\section{Author Contributions}

577 S.-F.S. conceived the idea. S.-F. S., I.-C. C., and W.-P. C. designed the methodology.

578 W.-P. C. performed the formal analysis. S.-F. S., I.-C. C., and W.-P. C. wrote the

579 paper. All authors discussed results and provided input and edits on the manuscript.

580

581 Corresponding Author

582 Correspondence to I-Ching Chen and Sheng-Feng Shen.

583

584 Competing interests

585 The authors declare no competing interests. 
(a)

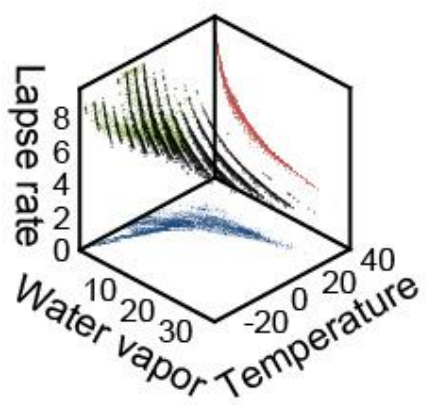

(c) Mean water vapor

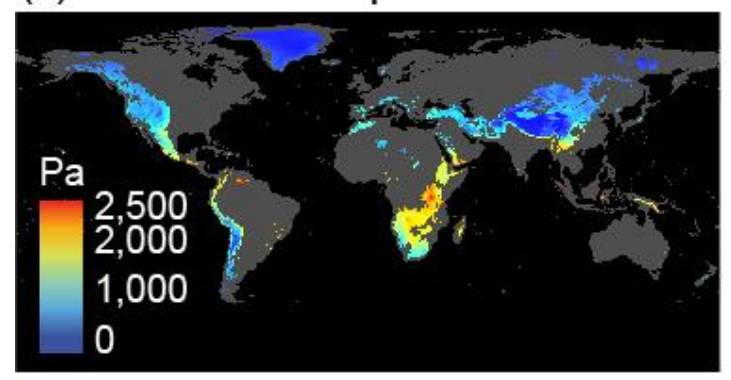

(b) Mean temperature

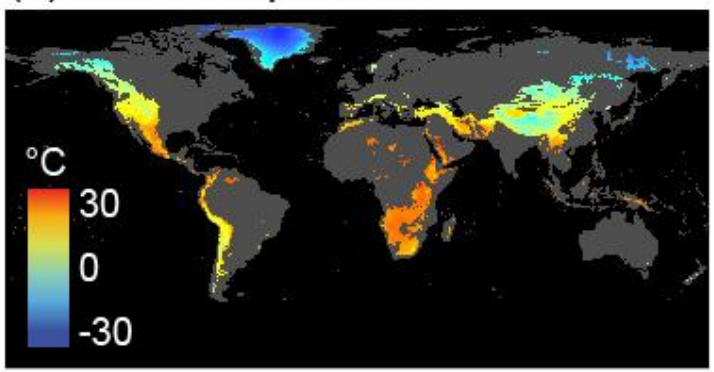

(d) Moist adiabatic lapse rate

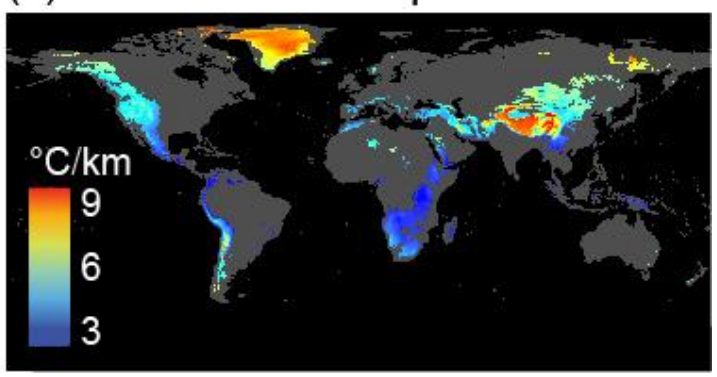

591 Figure 1| The foundation of moist adiabatic lapse rate for assessing climate

592 velocity in global mountains. (a) The nonlinear effect of surface temperature and

593 water vapor on lapse rate. The mean surface temperature (b) and water vapor (c) and

594 derived mean moist adiabatic lapse rates (2011-2015) in global mountains (d). 
(a) Surface temperature change

(b) Sea surface temp. change

(c) Climate velocity
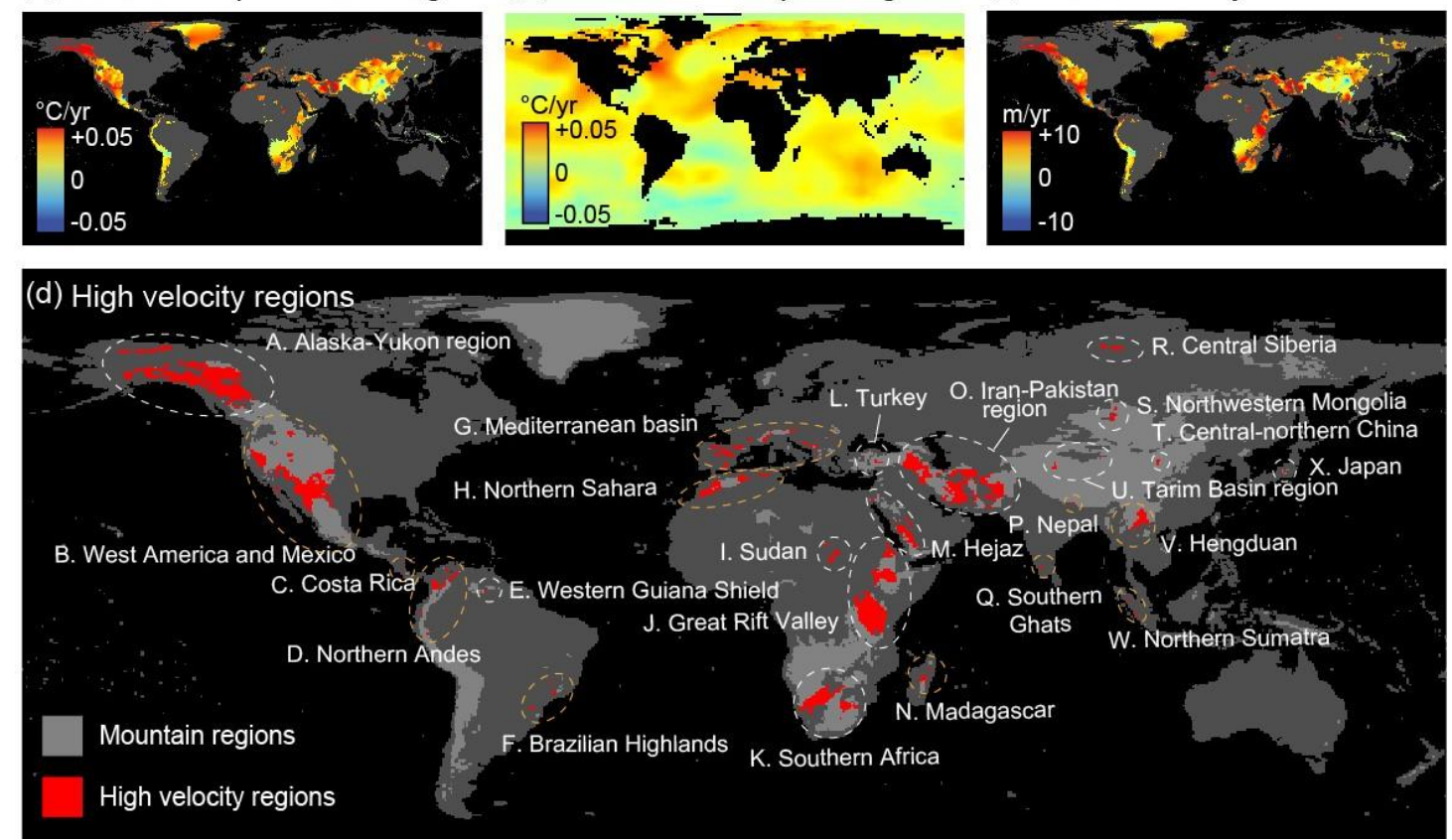

597 Figure 2|The velocity of climate change in global mountains from 1971 to 2015.

598 Terrestrial (a) and sea (b) surface temperature change (1971-1975 V.S. 2011-2015)

599 and derived elevational climate velocities in mountains (c). (d) The high climate-

600 velocity mountains are defined as where the isotherms have shifted more than one

601 standard deviation of the global mean value (higher than $8.45 \mathrm{~m} \mathrm{yr}^{-1}$ ). 

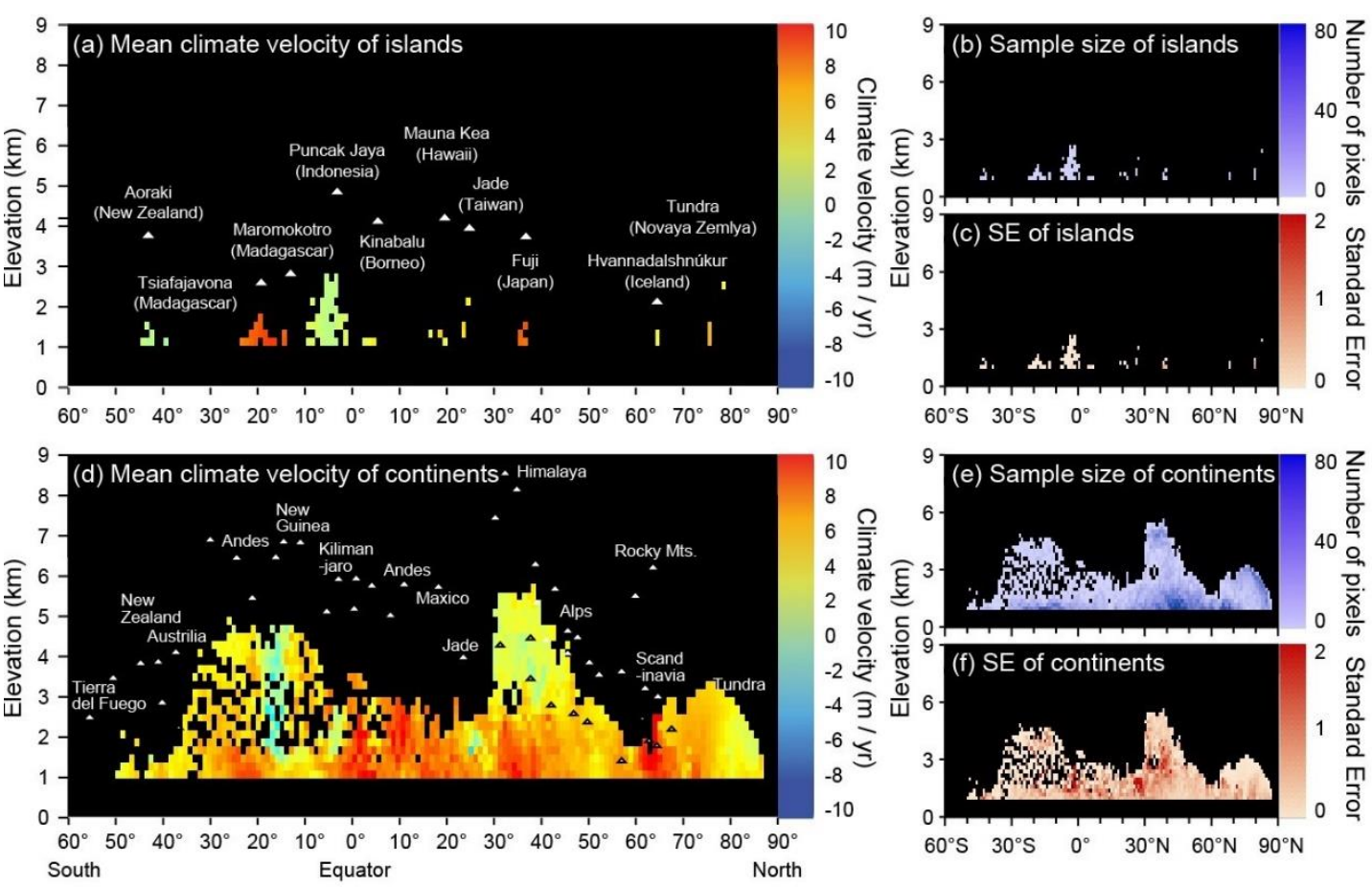

604 Figure 3| The velocity of climate change (1971-2015) in mountain islands (a, b, c)

605 and along latitude-elevation gradients (d, e, f). Please see the Supplementary

606 Method and Extended Data Fig. 3 for how to project a latitude-longitude map on a

607 latitude-elevation map. Mountain summits are labeled for reference. Results that

608 include the full $20^{\text {th }}$ century (1901-2015) can be found in Supplementary Fig. $1 \& 2$. 


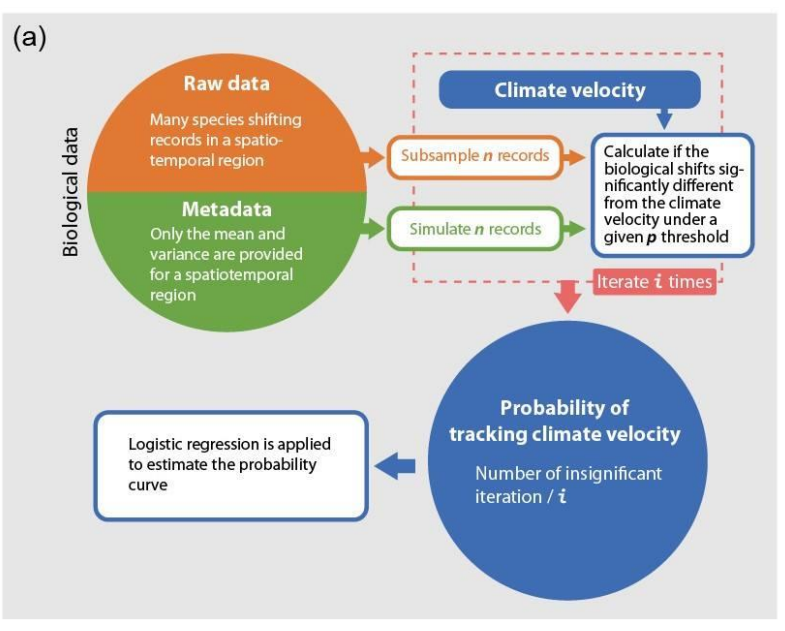

(c) $p=0.05$

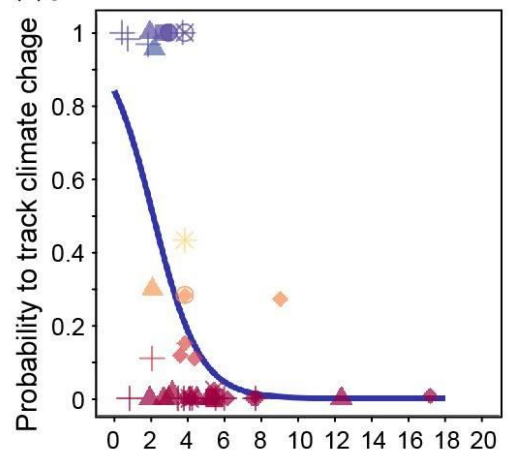

(d) $p=0.01$

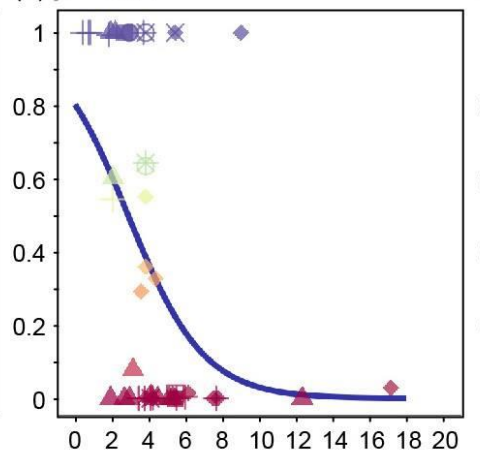

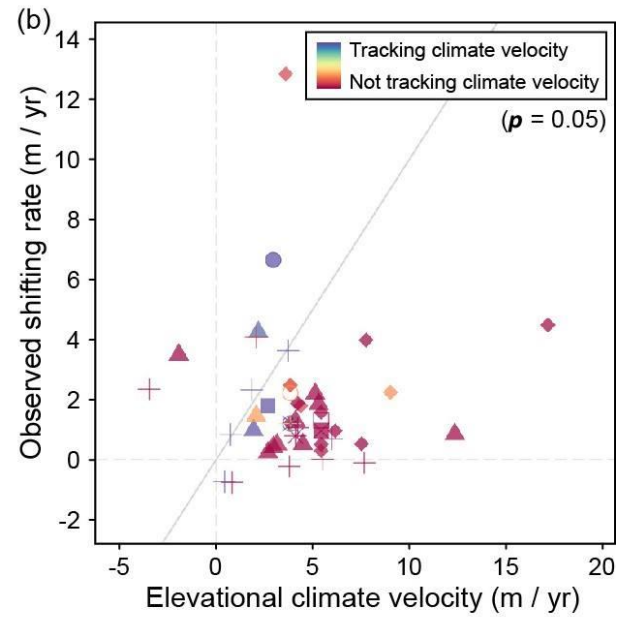

(e) $p=0.001$

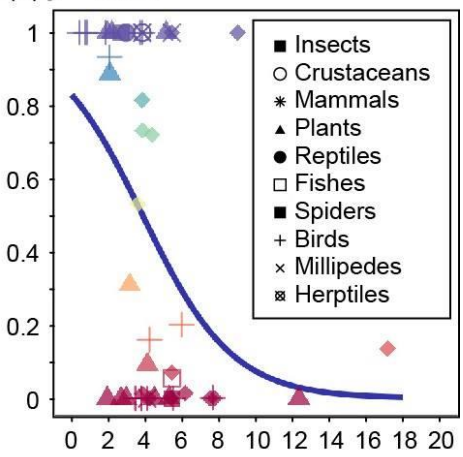

611 Figure 4|The probability of tracking climate velocities for mountain species. (a)

612 The diagram summarizing how the probability of tracking climate velocities was

613 calculated $(i=1000)$ (b) The diagonal diagram for observed range shifts for mountain

614 species and corresponding climate velocities. Blue labels represent cases that species 615 track climate successfully (color-coded under $p=0.05$ threshold). (c-e) The different 616 probabilities of species tracking climate velocity under different $p$ thresholds. Only 617 mean values are shown here. Panel c-e share the same color legend with panel b. For 618 raw data points, please see Extended Data Fig. 9 for details. 
622 Extended data figures and tables

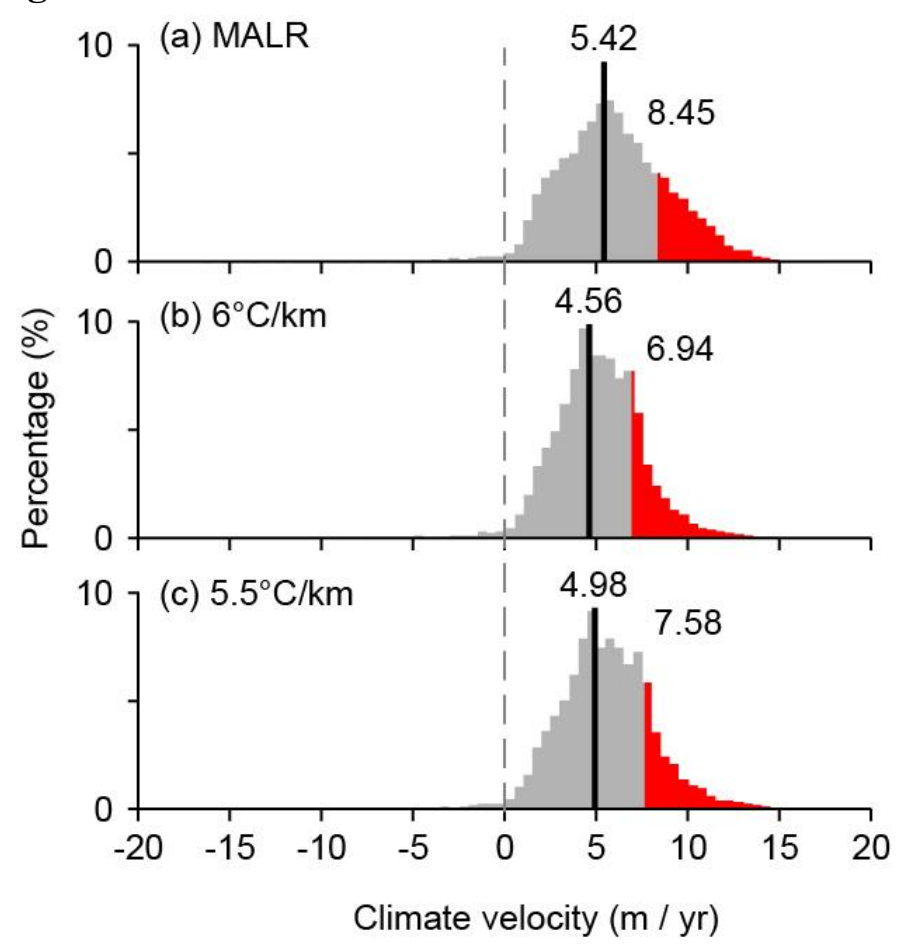

625 Extended Data Figure 1| Climate change velocity (1971-2015) derived from the

626 MALR formula (a) and average lapse rates (b-c). (a) The histogram of MALR. b-

627 c, Histograms derived from constant lapse rates $6{ }^{\circ} \mathrm{C} \mathrm{km}^{-1}$ (b) and $5.5^{\circ} \mathrm{C} \mathrm{km}^{-1}$ (c). The

628 dashed and solid lines represent the zero velocity and the mean velocity, respectively.

629 The red regions indicate the seriously warming regions (exceeding 1 standard

630 deviation). The values labeled above the solid lines and red regions are the mean

631 velocity and the minimum velocity of the seriously warming regions. The result of $63220^{\text {th }}$ century (1901-2015) can be found in Supplementary Fig. 2. 

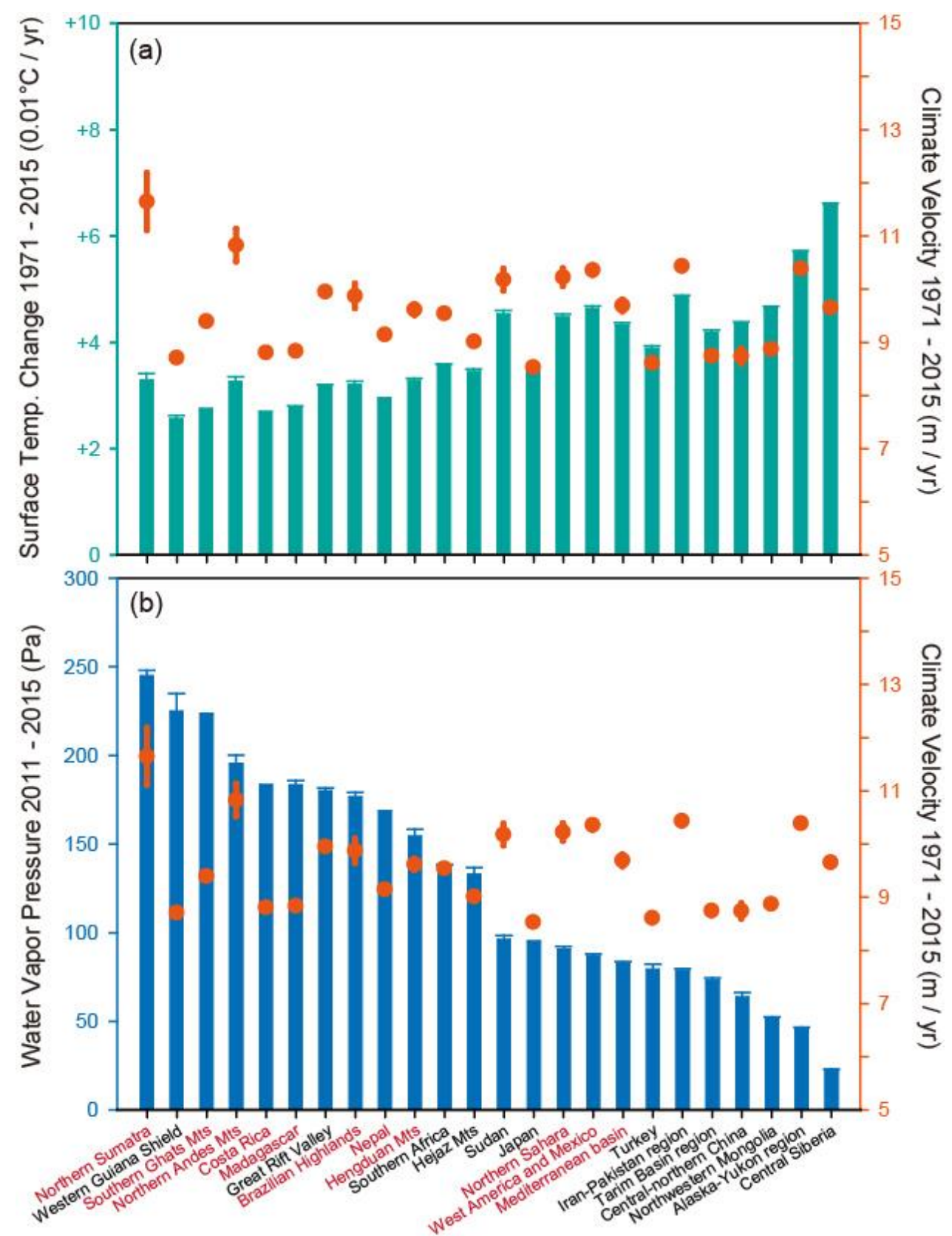
Extended Data Figure 2| The rising temperature and mean water vapor of the 17

635 high climate velocity regions in global mountains. For each region, orange dots

636 denote the climate velocity (1971-2015), green bar represent surface temperature

637 change (1971-1975 V.S. 2011-2015) (a); blue bars represent mean water vapor

638 pressure (2011-2015) (b). Biodiversity hotspot regions are labeled in red. Detailed

639 information on each region can be found in Supplementary Table 1 \& Data

640 availability section.

641 

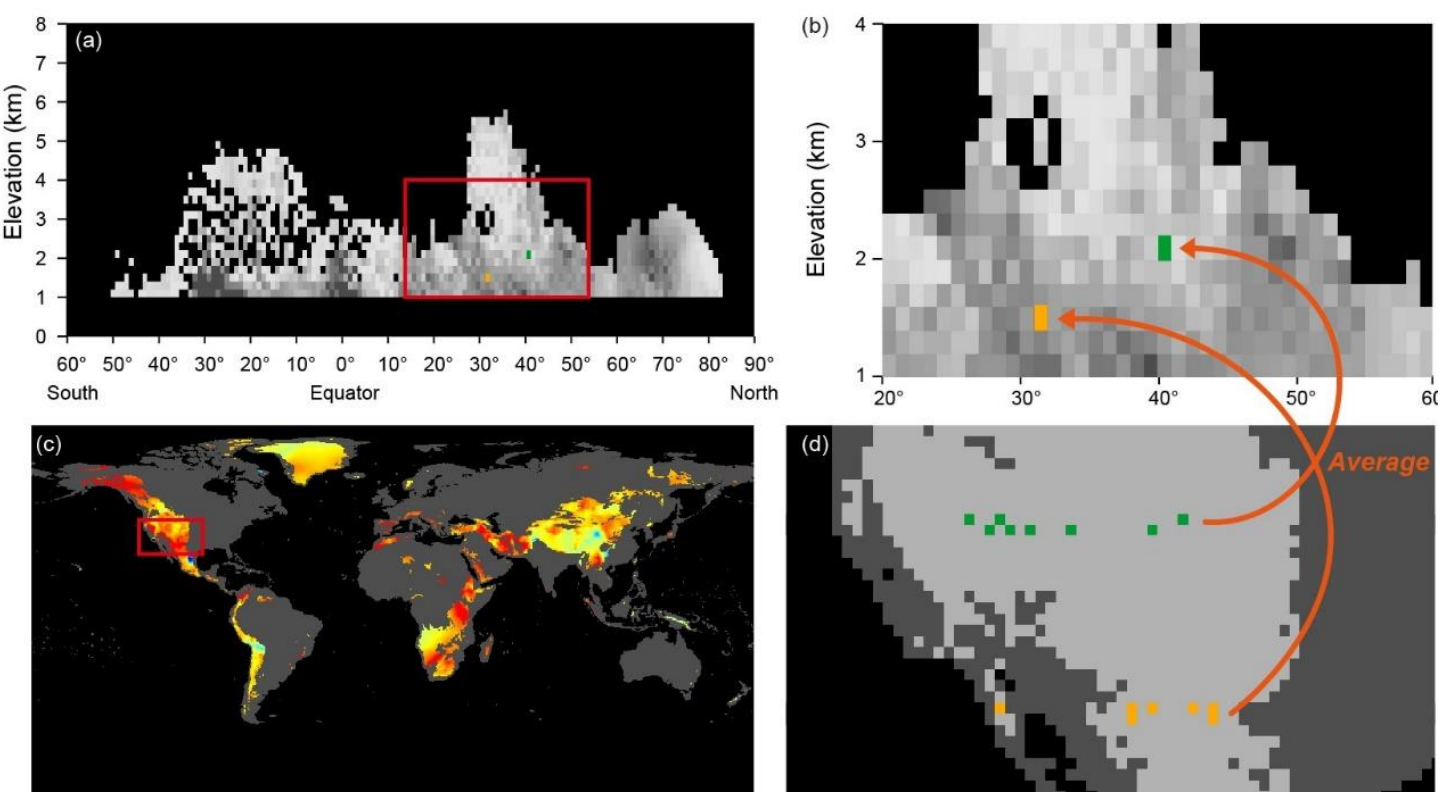

644

645 Extended Data Figure 3|Illustrations explaining how to project latitude-longitude

646 maps onto latitude-elevation maps. (a) a gray-scale latitude-elevation map as Fig.

$6473 \mathrm{~b}$; the red box is shown in b. (c) a latitude-elevation map; the red box is shown in $\mathbf{d}$.

648 (d) The green pixels represent the latitudinal band of $40^{\circ}$ and the altitudinal band of

$6492,000-2,200 \mathrm{~m}$; yellow pixels represent the latitudinal band of $31^{\circ}$ and the altitudinal

650 band of 1,400-1,600 m. The green and yellow pixels in $\mathbf{d}$ are averaged to the green

651 and yellow pixels in $\mathbf{b}$. 

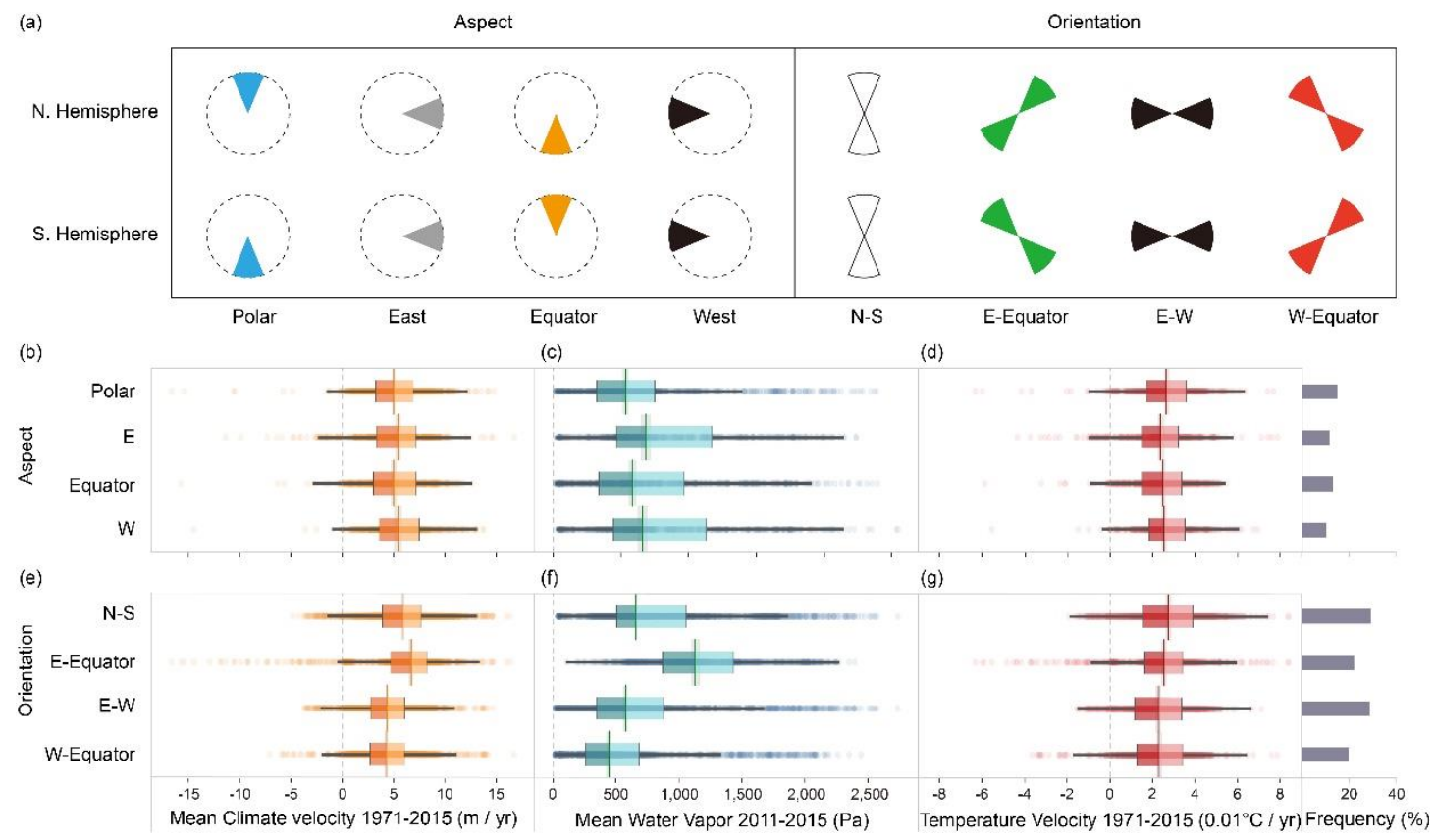

655 Extended Data Figure 4| The definition mountain aspects and orientations (a)

656 and associated mean climate velocity (b,e), mean water vapor (c,f), temperature

657 change (d,g). Median and its 95\% confidence interval is shown at the center of each 658 box. 


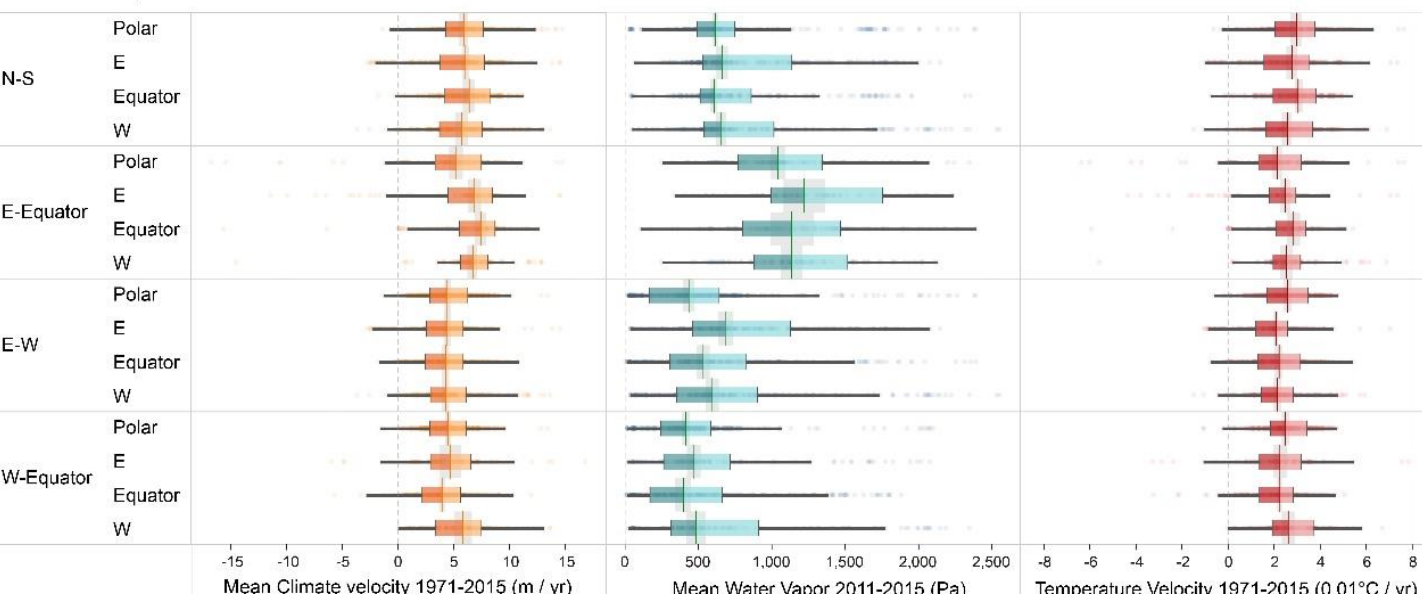

661 Extended Data Figure 5| Combined effect of mountain orientation and aspect on 662 mean climate velocity, mean water vapor, and temperature change. Median and 663 its $95 \%$ confidence interval is shown at the center of each box. 


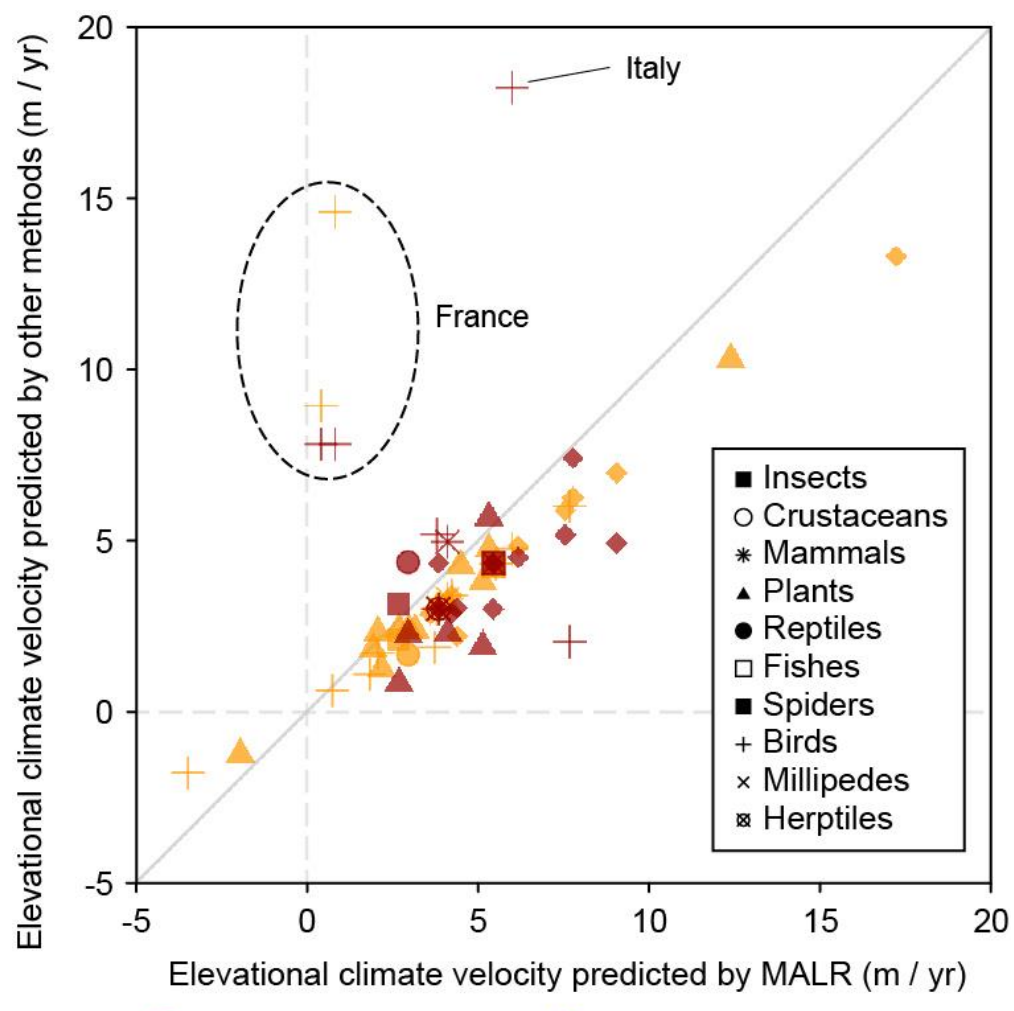

Empirical lapse rates A globally averaged lapse rate

666 Extended Data Figure 6| Comparison among elevational climate velocity derived 667 from MALR, a globally averaged lapse rate of $5.5^{\circ} \mathrm{C} / \mathrm{km}$ (yellow) and empirical 668 lapse rates in the original paper (red). The regions of outliers are labelled. 
(a)

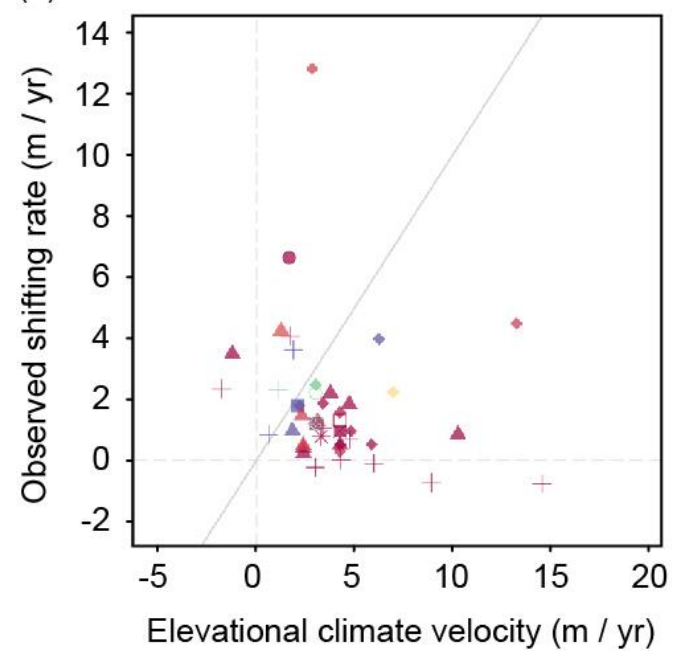

(c)

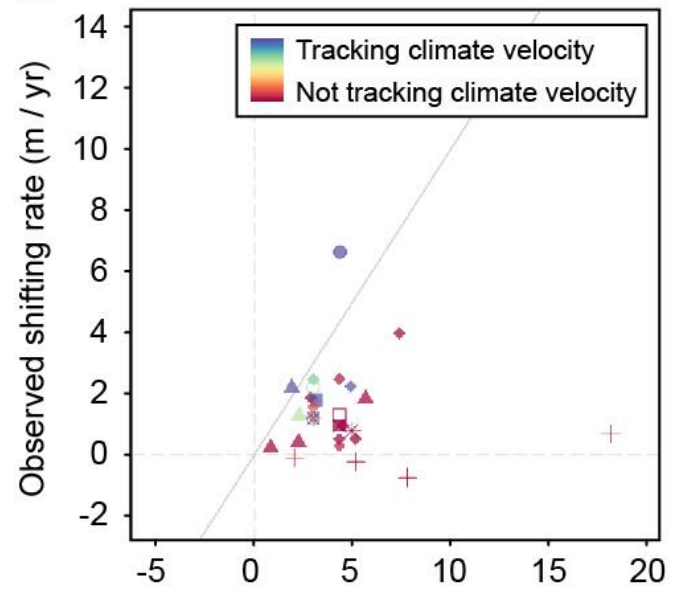

(b)

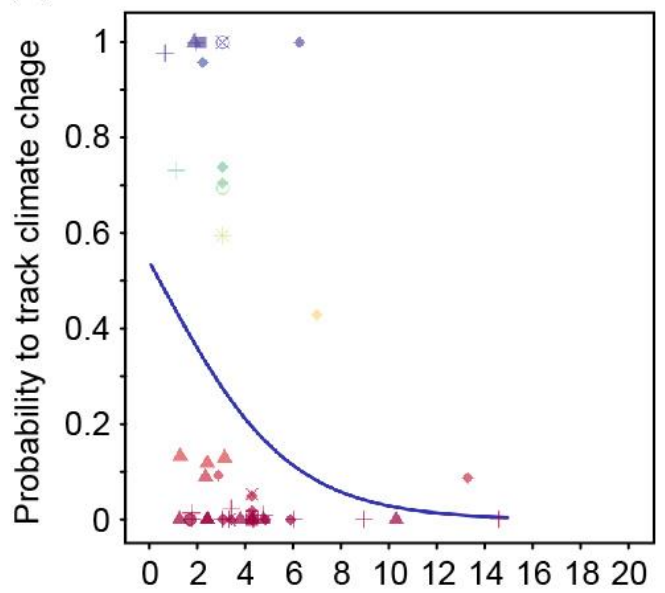

Nondirectional elevational climate velocity $(\mathrm{m} / \mathrm{yr})$

(d)

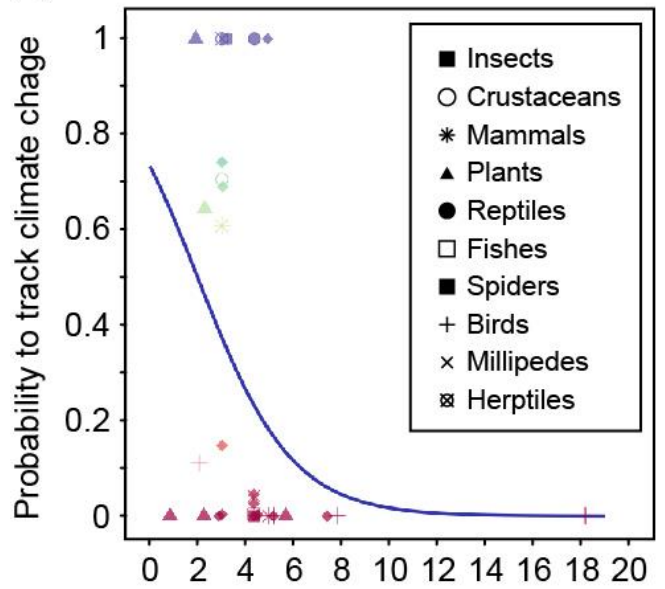

Nondirectional elevational climate velocity $(\mathrm{m} / \mathrm{yr})$

671 Extended Data Figure 7| The maximum trackable climate velocity based on (a, b)

672 constant lapse rate $\left(5.5^{\circ} \mathrm{C} / \mathrm{km}\right)$ and $(\mathrm{c}, \mathrm{d})$ empirical lapse rates in the original

673 paper. The relationships between observed shifting rate and elevational climate

674 velocity are shown in a and c. Only mean values are shown here. The probabilities

675 that species may track climate velocity are shown in $\mathbf{b}$ and $\mathbf{d}$. 


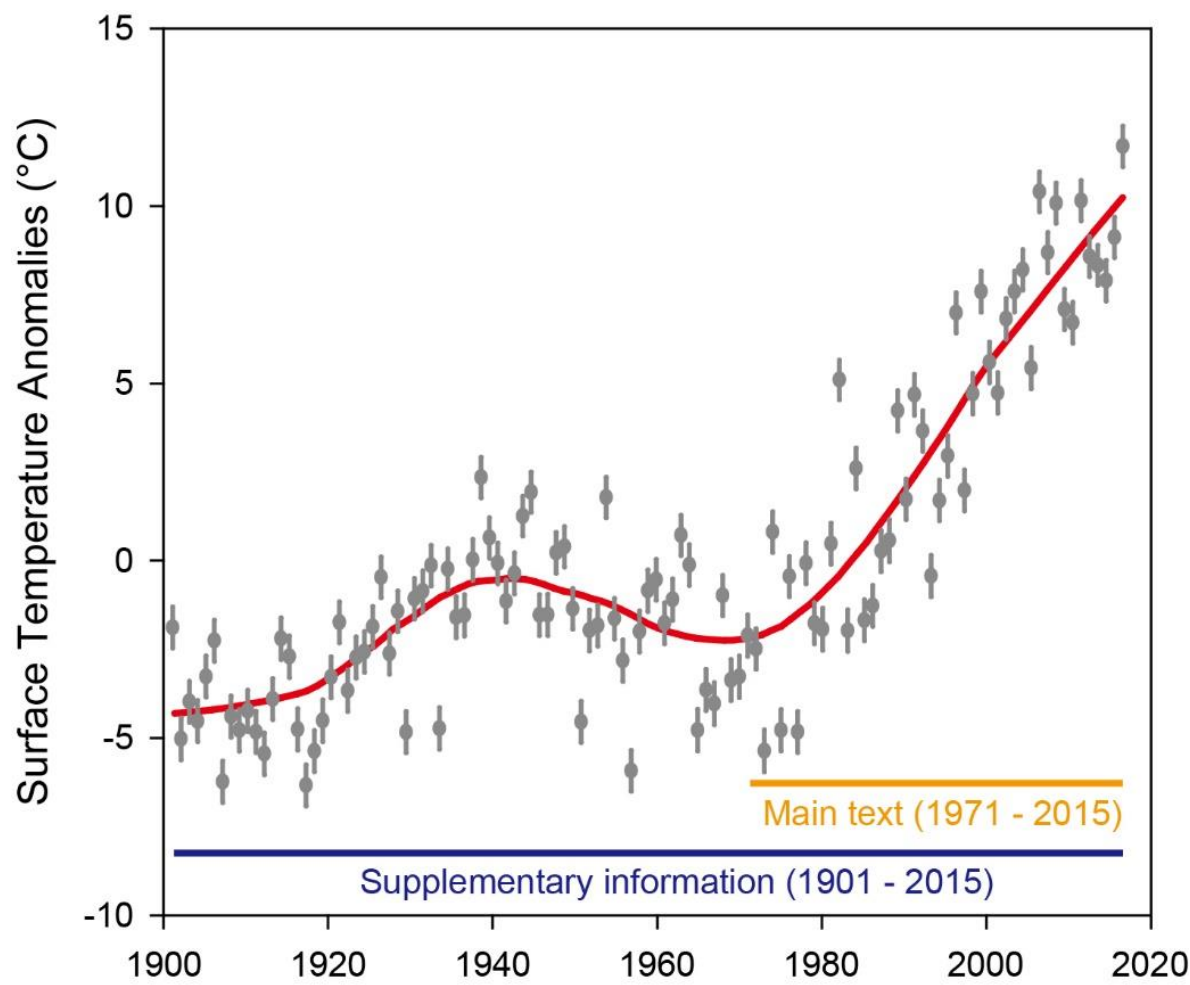

678

679 Extended Data Figure 8|The temporal extents we used in this study and an

680 example explaining how we derived climate velocity through a period of time.

681 The temperature trend from 1900 to 2015, and the target periods discussed in our

682 main text and supplementary materials are labeled as orange and blue bars,

683 respectively. 


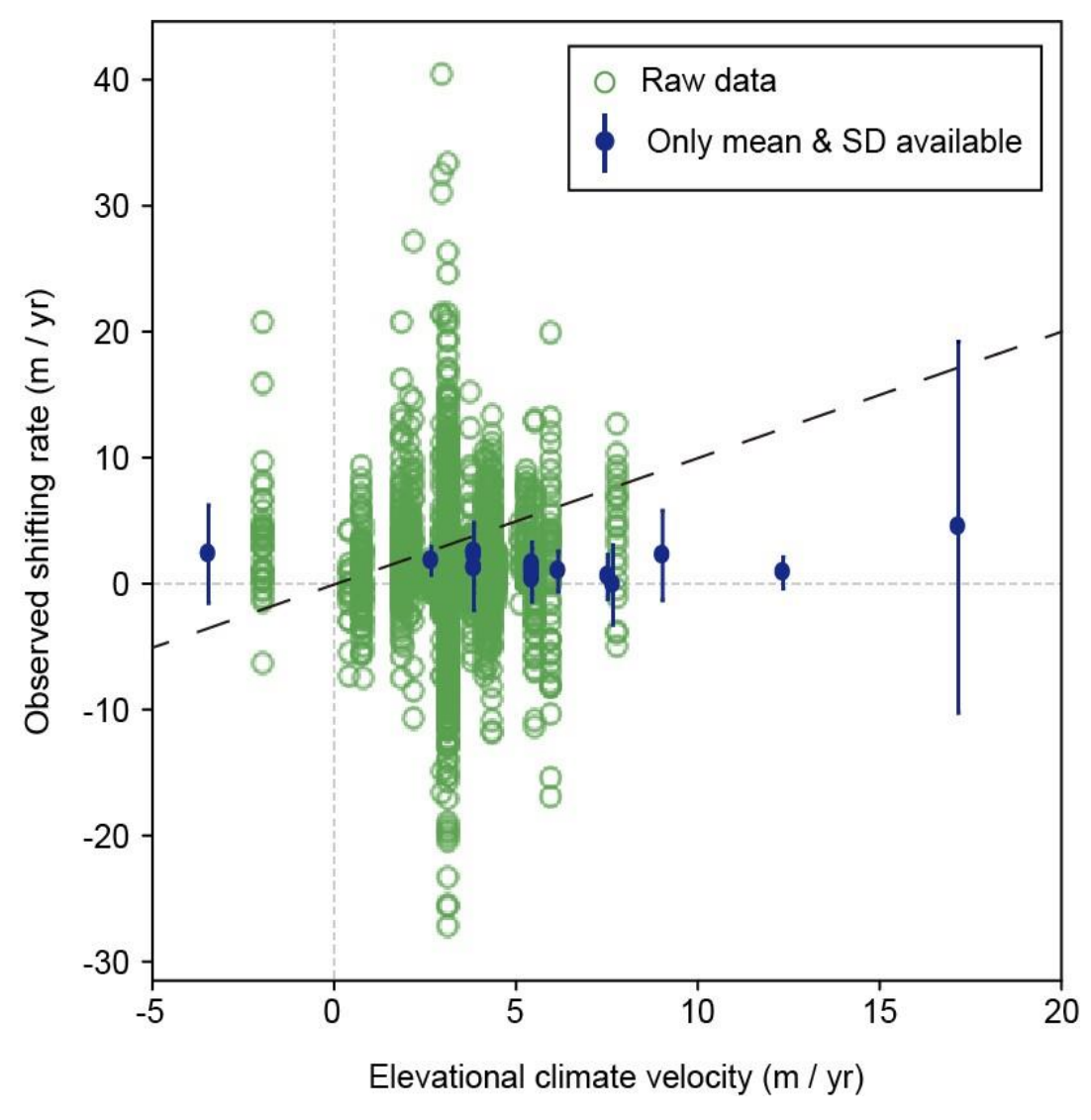

687 Extended Data Figure 9|Raw biological data points used in our analyses. All data 688 points from papers that provided raw data are shown (in green). Otherwise, mean and 689 standard deviation (reported in the original paper) are shown (in blue). Since a 690 proportion of original reports providing only mean and variance from a location, the 691 number of data points are highly overlapped. See Supplementary Table S2 for the 692 corresponding information and Data availability section for the dataset. 
(a)
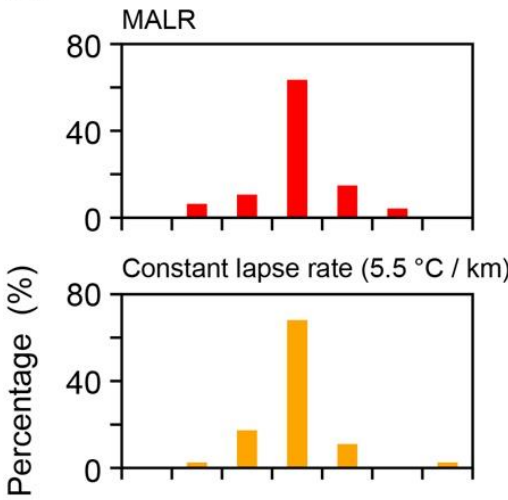

Local constant lapse rate

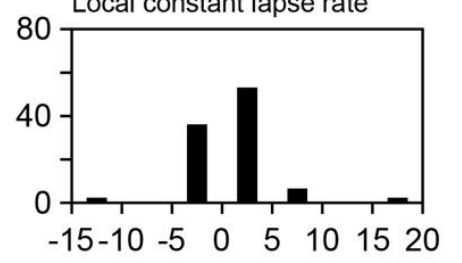

694

695

696 Extended Data Figure 10| Residual frequency distribution and the probability of (b)

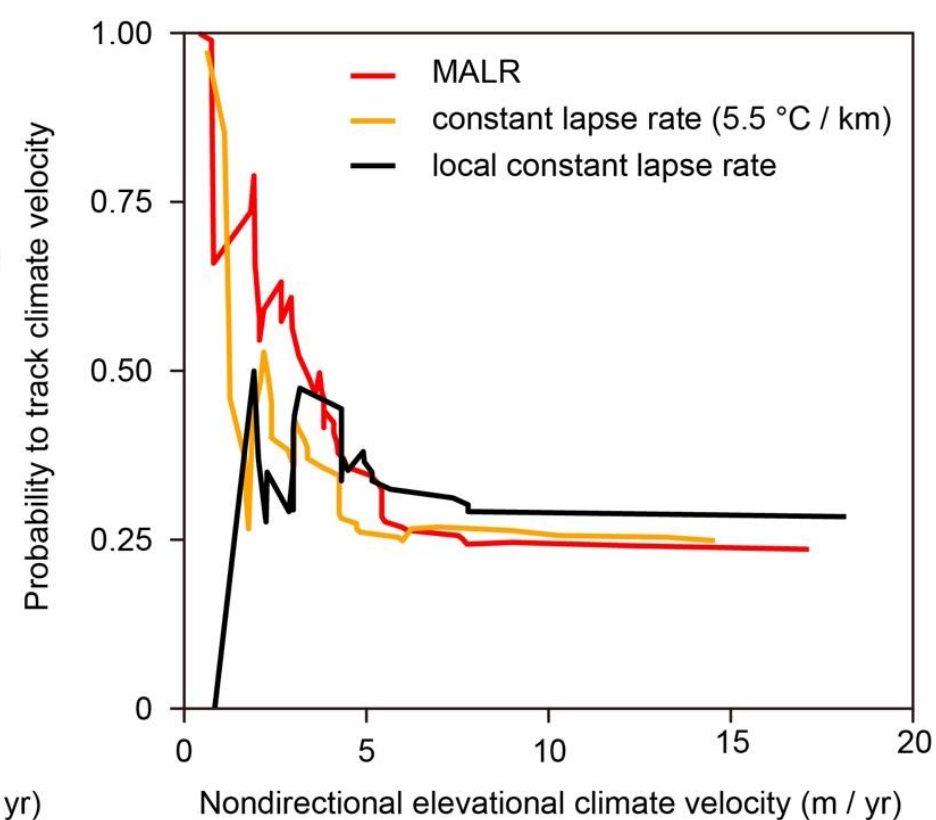
climate tracking and climate velocity under different lapse rate calculations. (a)

The residual frequency distribution simply derived from the difference between mean of observed range shift velocity and predicted climate velocity. This result shows clearly how better the climate velocity calculated by MALR, but it contains bias because it compares only the mean value of observed records (ignoring the variance of observed records). (b) an advanced analysis showing how climate velocity be tracked under different lapse rate. Please see Supplementary Methods for details. 

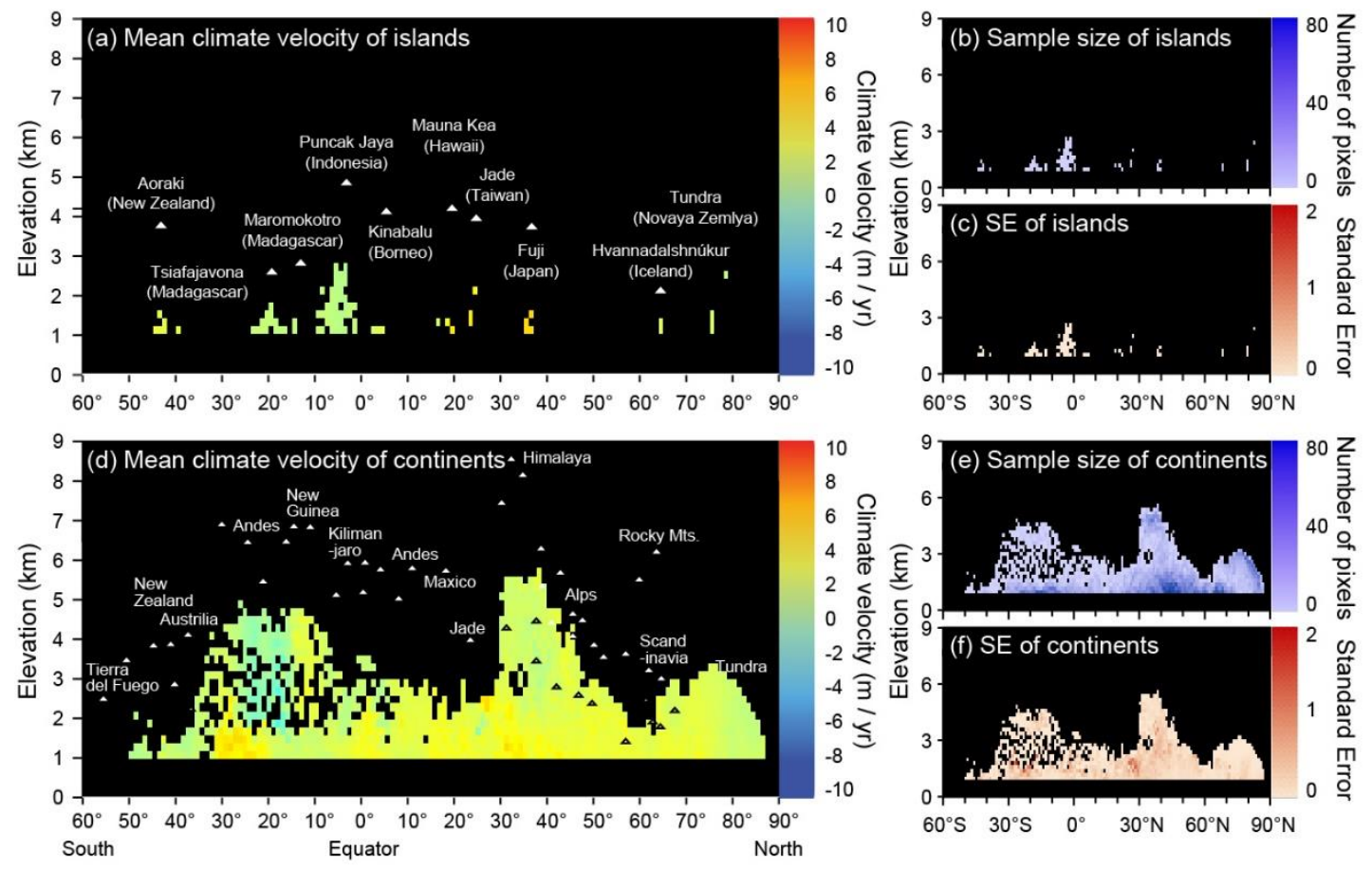

707

708 Supplementary Figure 1| Projections of the climate velocity (1901-2015) in global

709 mountain regions of $(\mathbf{a}, \mathbf{b}, \mathbf{c})$ islands and $(\mathbf{c}, \mathbf{d}, \mathbf{e})$ continents. Please see the

710 Supplementary Method and Extended Data Fig. 3 for how to project a latitude-

711 longitude map on a latitude-elevation map. Some mountains are labeled as triangles.

712 The sample size $(\mathbf{b}, \mathbf{e})$ and standard error $(\mathbf{c}, \mathbf{f})$ are shown. 


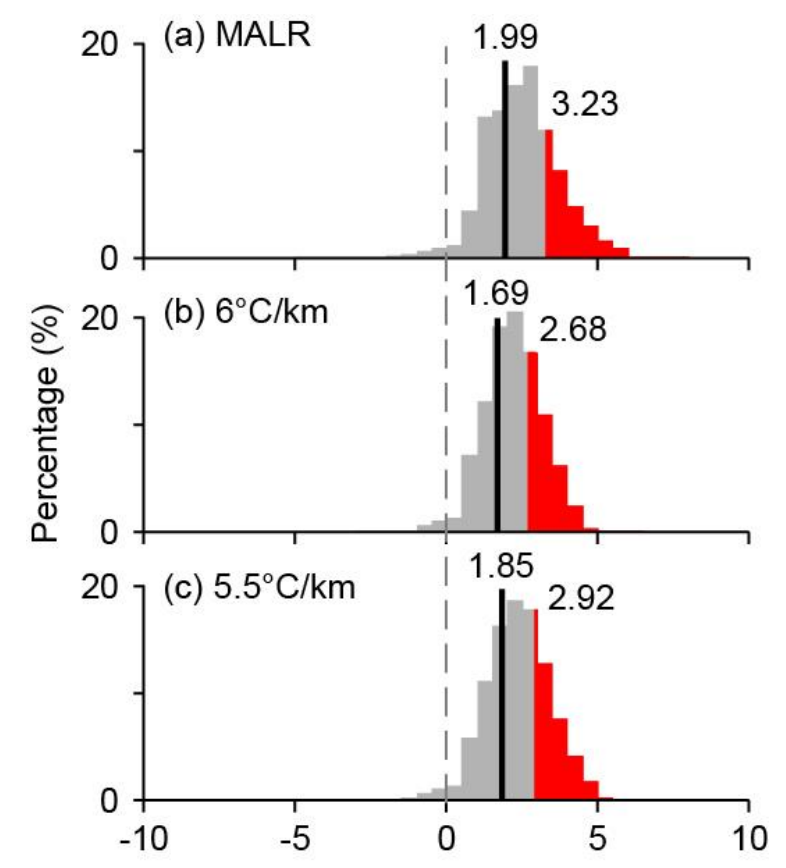

Climate velocity $(\mathrm{m} / \mathrm{yr})$

716 Supplementary Figure 2|Climate change velocity (1901-2015) derived from the

717 MALR formula (a) and average lapse rates (b - c). (a) The histogram of MALR. b-

718 c, Histograms derived from constant lapse rates $6{ }^{\circ} \mathrm{C} \mathrm{km}^{-1}$ (b) and $5.5^{\circ} \mathrm{C} \mathrm{km}^{-1}$ (c). The

719 dashed and solid lines represent the zero velocity and the mean velocity, respectively.

720 The red regions indicate the seriously warming regions (exceeding 1 standard

721 deviation). The values labeled above the solid lines and red regions are the mean

722 velocity and the minimum velocity of the seriously warming regions.

723 

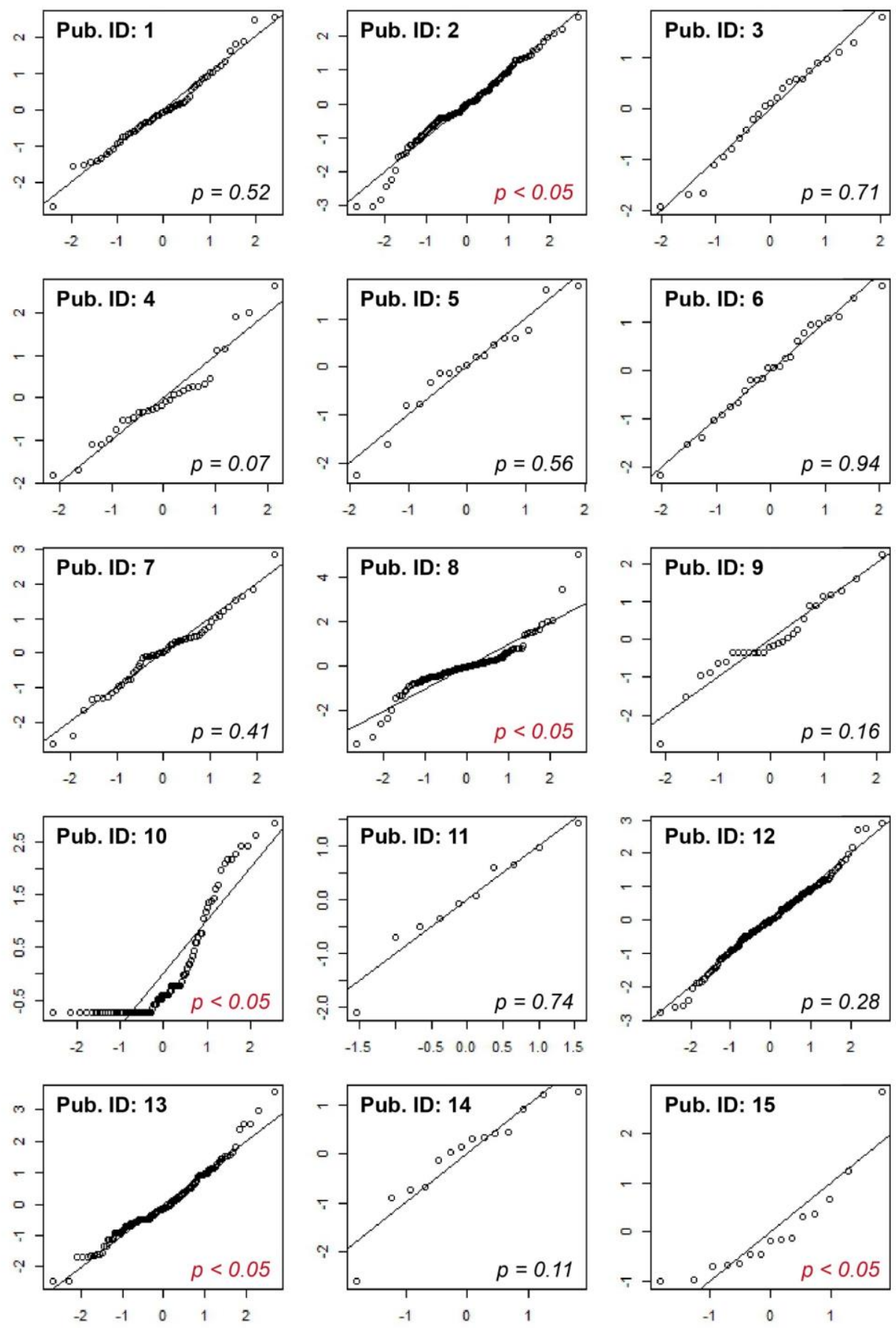

Supplementary Figure 3|Normality tests and qq plots for all biological raw

726 datasets. Those datasets only reporting statistical summaries are not included. The p-

727 values of Shapiro-Wilk normality tests for each dataset are shown in the lower-right 728 corner of each panel. 

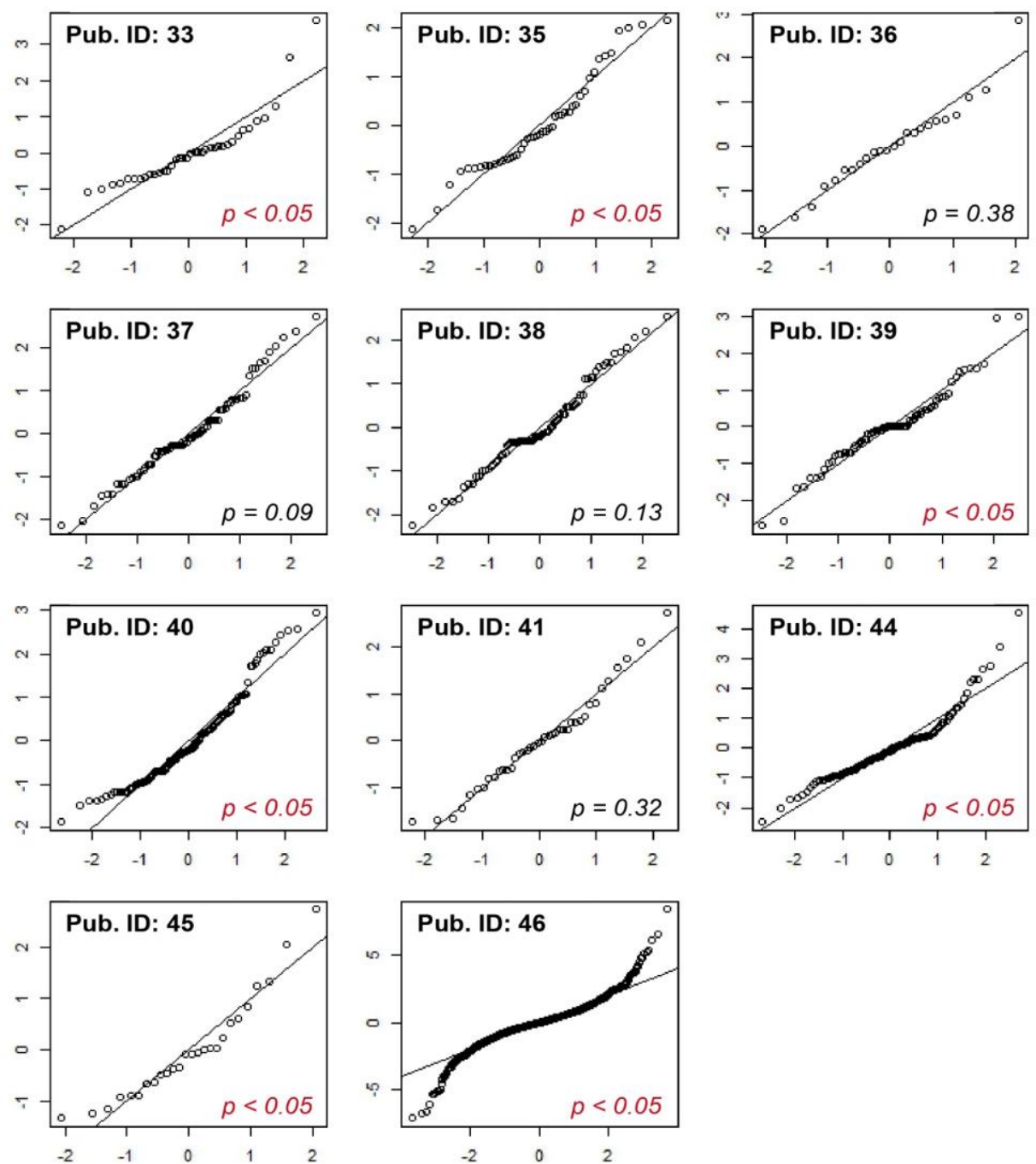

730 Supplementary Figure 3| (Continued) the normality tests and qq plots for all 731 biological raw datasets.

732 
734 Supplementary Table 1|Statistical information on major regions of high-velocity regions

\begin{tabular}{|c|c|c|c|c|c|c|c|c|c|c|c|c|c|}
\hline \multirow{2}{*}{ ID } & \multirow{2}{*}{$\begin{array}{c}\text { Region } \\
\text { Alaska-Yukon region }\end{array}$} & \multirow{2}{*}{$\begin{array}{l}\text { Area* } \\
26.28\end{array}$} & \multicolumn{2}{|c|}{$\begin{array}{c}\text { MALR } \dagger \\
(2011-2015)\end{array}$} & \multicolumn{2}{|c|}{$\begin{array}{c}\text { MAP }+ \\
(1971-2015)\end{array}$} & \multicolumn{2}{|c|}{$\begin{array}{l}\text { Water vapor§ } \\
(2011-2015)\end{array}$} & \multicolumn{2}{|c|}{$\begin{array}{l}\text { Surface temp. } \\
\text { change\| } \\
\text { (1971-2015) }\end{array}$} & \multicolumn{2}{|c|}{ ElevationII } & \multirow{2}{*}{$\begin{array}{c}\text { BD.\# } \\
\text { hotspot } \\
\mathrm{N}\end{array}$} \\
\hline & & & 5.47 & $(0.02)$ & 366.72 & $(8.71)$ & 46.12 & $(0.38)$ & 5.69 & $(0.04)$ & 1299.29 & (10.84) & \\
\hline B & $\begin{array}{l}\text { West America and } \\
\text { Mexico }\end{array}$ & 14.84 & 4.46 & $(0.02)$ & 349.98 & (10.06) & 86.86 & $(1.27)$ & 4.63 & $(0.05)$ & 1498.11 & (19.44) & $\mathrm{Y}$ \\
\hline $\mathrm{C}$ & Costa Rica & 0.05 & 3.05 & (NA) & 3769.9 & (NA) & 183.27 & (NA) & 2.69 & (NA) & 1741 & (NA) & $\mathrm{Y}$ \\
\hline $\mathrm{D}$ & Northern Andes Mts & 1.73 & 3.02 & $(0.03)$ & 1718.4 & $(109.76)$ & 195.09 & $(4.92)$ & 3.26 & $(0.09)$ & 1612.94 & $(63.36)$ & $\mathrm{Y}$ \\
\hline $\mathrm{E}$ & Western Guiana Shield & 0.15 & 2.93 & $(0.07)$ & 2519.71 & $(387.52)$ & 224.72 & (10.19) & 2.55 & $(0.07)$ & 1125 & (73.38) & $\mathrm{N}$ \\
\hline $\mathrm{F}$ & Brazilian Highlands & 0.54 & 3.24 & $(0.02)$ & 1441.88 & $(24.15)$ & 176.3 & $(2.78)$ & 3.2 & $(0.07)$ & 1108.55 & (20.34) & $\mathrm{Y}$ \\
\hline $\mathrm{G}$ & Mediterranean basin & 3.75 & 4.46 & $(0.02)$ & 770.9 & $(39.87)$ & 82.56 & $(0.96)$ & 4.32 & $(0.05)$ & 1243.74 & $(29.71)$ & $\mathrm{Y}$ \\
\hline $\mathrm{H}$ & Northern Sahara & 3.16 & 4.38 & $(0.03)$ & 295.7 & $(9.43)$ & 90.47 & $(1.81)$ & 4.47 & $(0.07)$ & 1352.42 & $(40.95)$ & $\mathrm{Y}$ \\
\hline I & Sudan & 0.99 & 4.46 & $(0.05)$ & 263.3 & $(28.35)$ & 95.84 & $(2.63)$ & 4.53 & $(0.07)$ & 1104.4 & $(25.32)$ & $\mathrm{N}$ \\
\hline $\mathrm{J}$ & Great Rift Valley & 15.48 & 3.21 & $(0.01)$ & 868.95 & $(16.03)$ & 179.74 & $(1.75)$ & 3.19 & $(0.02)$ & 1451.66 & (22.08) & $\mathrm{N}$ \\
\hline
\end{tabular}




\begin{tabular}{|c|c|c|c|c|c|c|c|c|c|c|c|c|c|}
\hline K & Southern Africa & 7.25 & 3.74 & $(0.03)$ & 308.57 & $(12.9)$ & 135.96 & $(2.33)$ & 3.56 & $(0.03)$ & 1180.22 & $(13.73)$ & $\mathrm{N}$ \\
\hline $\mathrm{L}$ & Turkey & 0.3 & 4.5 & $(0.05)$ & 364 & $(13.17)$ & 79 & $(3.26)$ & 3.88 & $(0.06)$ & 1445 & (119.39) & $\mathrm{N}$ \\
\hline M & Hejaz Mts & 2.86 & 3.82 & $(0.06)$ & 121.76 & $(5.58)$ & 132.63 & $(4.04)$ & 3.44 & $(0.06)$ & 1259.76 & $(32.08)$ & $\mathrm{N}$ \\
\hline $\mathrm{N}$ & Madagascar & 0.69 & 3.16 & $(0.01)$ & 1423.1 & (73.13) & 183.09 & $(2.74)$ & 2.79 & $(0.01)$ & 1231.71 & $(40.52)$ & $\mathrm{Y}$ \\
\hline $\mathrm{O}$ & Iran-Pakistan region & 17.11 & 4.66 & $(0.03)$ & 221.42 & $(6.45)$ & 78.46 & $(1.17)$ & 4.85 & $(0.04)$ & 1549.16 & $(21.03)$ & $\mathrm{N}$ \\
\hline $\mathrm{P}$ & Nepal & 0.05 & 3.23 & (NA) & 1616.12 & (NA) & 168.53 & (NA) & 2.96 & (NA) & 1467 & (NA) & $\mathrm{Y}$ \\
\hline Q & Southern Ghats Mts & 0.1 & 2.92 & (NA) & 1054.4 & (NA) & 223.46 & (NA) & 2.75 & (NA) & 1199 & (NA) & $\mathrm{Y}$ \\
\hline $\mathrm{R}$ & Central Siberia & 0.79 & 6.82 & $(0.03)$ & 373.95 & $(5.87)$ & 22.51 & $(0.4)$ & 6.58 & $(0.04)$ & 1092 & $(19.15)$ & $\mathrm{N}$ \\
\hline $\mathrm{S}$ & $\begin{array}{l}\text { Northwestern } \\
\text { Mongolia }\end{array}$ & 0.79 & 5.24 & $(0.02)$ & 360.49 & $(24.49)$ & 51.71 & $(0.81)$ & 4.65 & $(0.02)$ & 1233.13 & $(40.5)$ & $\mathrm{N}$ \\
\hline $\mathrm{T}$ & Central-northern China & 0.2 & 4.99 & $(0.07)$ & 163.82 & $(7.25$ & 63.58 & $(2.71$ & 4.36 & $(0.02$ & 1309.75 & $(83.26)$ & $\mathrm{N}$ \\
\hline $\mathrm{U}$ & Tarim Basin region & 0.39 & 4.78 & $(0.05)$ & 64.66 & $(6.79)$ & 72.78 & $(1.69)$ & 4.18 & $(0.05)$ & 1263.5 & (19.17) & $\mathrm{N}$ \\
\hline V & Hengduan Mts & 2.27 & 3.4 & $(0.03)$ & 1001.3 & (19.89) & 154.06 & $(4.25)$ & 3.27 & $(0.05)$ & 1538.5 & $(51.97)$ & $\mathrm{Y}$ \\
\hline $\mathrm{W}$ & Northern Sumatra & 0.25 & 2.82 & $(0.02)$ & 2375.73 & $(239.68)$ & 244.57 & $(3.34)$ & 3.28 & $(0.14)$ & 1122 & $(26.14)$ & $\mathrm{Y}$ \\
\hline$X$ & Japan & 0.1 & 4.17 & (NA) & 1310.04 & (NA) & 95.09 & (NA) & 3.56 & (NA) & 1109.5 & (NA) & $\mathrm{N}$ \\
\hline
\end{tabular}


$735 *$ Percentage of each region divided by the total area of high-velocity regions in global mountains. (Unit: \%)

$736 \dagger$ Moist adiabatic lapse rate derived from mean temperature and mean water vapor. (Unit: ${ }^{\circ} \mathrm{C} / \mathrm{km}$; format: mean [S.E.])

737 \$ Mean annual precipitation. (Unit: $\mathrm{mm} / \mathrm{yr}$; format: mean [S.E.])

$738 \S$ Mean water vapor pressure; used as the parameter to derive MALR (2011-2015) in order to calculate climate velocity. (Unit: Pa; format: mean 739 [S.E.])

740 || Temperature velocity. (1971-1975 V.S. 2011-2015; Unit: $0.01^{\circ}{ }^{\circ} \mathrm{C} / \mathrm{yr}$; format: mean [S.E.])

741 II Averaged elevation. (Unit: meter; format: mean [S.E.])

742 \# Biodiversity hotspot. This cell is filled by "Y" for any regions with biodiversity hotspots $\left({ }^{45}\right)$. 
745 Supplementary Table 2|Biological datasets.

\begin{tabular}{|c|c|c|c|c|c|c|c|}
\hline Pub_ID & Location & $\begin{array}{l}\text { 1st yr of } 1 \text { st } \\
\text { investigation }\end{array}$ & $\begin{array}{l}\text { 2nd yr of } 1 \text { st } \\
\text { investigation }\end{array}$ & $\begin{array}{l}1 \text { st yr of } 2 \text { nd } \\
\text { investigation }\end{array}$ & $\begin{array}{l}\text { 2nd yr of 2nd } \\
\text { investigation }\end{array}$ & Taxon & Reference \\
\hline 1 & Switzerland & 1880 & 1920 & 1980 & 2005 & Plants & 46 \\
\hline 2 & Maylaysia(Mt. Kinabalu) & 1965 & 1965 & 2007 & 2007 & Insects & 2 \\
\hline 3 & Spain (Sierra de Guadarrama) & 1967 & 1973 & 2004 & 2004 & Insects & 47 \\
\hline 4 & Madagascar(Tsaratanana Massif) & 1993 & 1993 & 2003 & 2003 & Herptiles & 48 \\
\hline 5 & France (Giffre valley) & 1978 & 1980 & 2001 & 2002 & Aves & 49 \\
\hline 6 & France (Mont Ventoux alt.) & 1973 & 1974 & 2000 & 2001 & Aves & 49 \\
\hline 7 & Italy (Alta Valsessera) & 1992 & 1994 & 2003 & 2005 & Aves & 50 \\
\hline 8 & USA (New York State) & 1980 & 1985 & 2000 & 2005 & Aves & 51 \\
\hline 9 & USA (Yosemite Nationa Park) & 1914 & 1920 & 2003 & 2006 & Mammals & 52 \\
\hline 10 & Italy (Rhaetian Alps) & 1954 & 1958 & 2003 & 2005 & Plants & 53 \\
\hline 11 & USA (Mt. Santa Rosa,CA) & 1977 & 1977 & 2006 & 2007 & Plants & 54 \\
\hline 12 & West Europe (SW France) & 1905 & 1985 & 1986 & 2005 & Plants & 55 \\
\hline
\end{tabular}




\begin{tabular}{|c|c|c|c|c|c|c|c|}
\hline 13 & Switzerland (12 Mts in Grisons) & 1893 & 1893 & 2004 & 2004 & Plants & 41 \\
\hline 14 & Marion Island (sub-Antarctic) & 1965 & 1966 & 2005 & 2007 & Plants & 56 \\
\hline 15 & Czech Republic & 1951 & 1980 & 1995 & 2001 & Insects & 57 \\
\hline $16^{*}$ & UK (Great Britain) & 1970 & 1982 & 2004 & 2005 & Insects & 58 \\
\hline $17^{*}$ & UK (Great Britain) & 1970 & 1982 & 1995 & 1999 & Insects & 37 \\
\hline $18^{*}$ & UK (Great Britain) & 1970 & 1980 & 1990 & 2000 & Insects & 37 \\
\hline $19^{*}$ & UK (Great Britain) & 1960 & 1970 & 1985 & 1995 & Insects & 37 \\
\hline $20^{*}$ & UK (Great Britain) & 1960 & 1970 & 1985 & 1995 & Insects & 37 \\
\hline $21 *$ & UK (Great Britain) & 1965 & 1975 & 1990 & 2000 & Insects & 37 \\
\hline $22^{*}$ & UK (Great Britain) & 1965 & 1975 & 1985 & 1995 & Arachnids & 37 \\
\hline $23 *$ & UK (Great Britain) & 1965 & 1975 & 1990 & 2000 & Insects & 37 \\
\hline $24 *$ & UK (Great Britain) & 1965 & 1975 & 1990 & 2000 & Insects & 37 \\
\hline $25^{*}$ & UK (Great Britain) & 1965 & 1975 & 1990 & 2000 & Millipedes & 37 \\
\hline $26^{*}$ & UK (Great Britain) & 1960 & 1970 & 1985 & 1995 & Insects & 37 \\
\hline $27 *$ & UK (Great Britain) & 1965 & 1975 & 1990 & 2000 & Arachnids & 37 \\
\hline
\end{tabular}




\begin{tabular}{|c|c|c|c|c|c|c|c|}
\hline $28^{*}$ & UK (Great Britain) & 1960 & 1970 & 1985 & 1995 & $\begin{array}{l}\text { Malacostrac } \\
\text { a }\end{array}$ & 37 \\
\hline $29 *$ & UK (Great Britain) & 1965 & 1975 & 1990 & 2000 & Fishes & 37 \\
\hline $30^{*}$ & UK (Great Britain) & 1968 & 1972 & 1988 & 1991 & Aves & 37 \\
\hline $31^{*}$ & UK (Great Britain) & 1960 & 1970 & 1985 & 1995 & Mammals & 37 \\
\hline $32 *$ & UK (Great Britain) & 1960 & 1970 & 1985 & 1995 & Herptiles & 37 \\
\hline 33 & Peru & 2003 & 2004 & 2007 & 2008 & Plants & 59 \\
\hline $34 *$ & Peru & 1969 & 1969 & 2010 & 2010 & Aves & 60 \\
\hline 35 & Norway & 1922 & 1932 & 2008 & 2008 & Plants & 61 \\
\hline 36 & Taiwan & 1969 & 1969 & 2006 & 2006 & Plants & 43 \\
\hline 37 & USA (Lassen,CA) & 1924 & 1928 & 2006 & 2007 & Aves & 42 \\
\hline 38 & USA (Yosemite,CA) & 1915 & 1919 & 2003 & 2004 & Aves & 42 \\
\hline 39 & USA (Southern Sierra,CA) & 1911 & 1911 & 2008 & 2009 & Aves & 42 \\
\hline 40 & India & 1849 & 1850 & 2007 & 2010 & Plants & 62 \\
\hline 41 & USA & 1977 & 1981 & 2006 & 2011 & Aves & 63 \\
\hline
\end{tabular}




\begin{tabular}{|l|l|l|l|l|l|l|l|}
\hline $42^{*}$ & France (South-western Alps) & 1992 & 1993 & 2007 & 2007 & Insects & 38 \\
\hline $43^{*}$ & Spain (Sierra Nevada) & 1981 & 1982 & 2006 & 2007 & Insects & 38 \\
\hline 44 & New Guinean (Mt. Karimui) & 1955 & 1964 & 2002 & 2011 & Aves & 8 \\
\hline 45 & New Guinean (Karkar Island) & 1959 & 1968 & 2002 & 2011 & Aves & 8 \\
\hline 46 & USA (California) & 1895 & 1970 & 1971 & 2009 & Plants & 64 \\
\hline $47^{*}$ & Canada & 1970 & 1970 & 2012 & 2012 & Plants & 65 \\
\hline
\end{tabular}

* Only mean and variance/standard deviation/error are available from the literature 
747 Supplementary Table 3 |The probability of tracking climate velocity based on

748 Wilcoxon signed-rank test under different sample sizes (n).

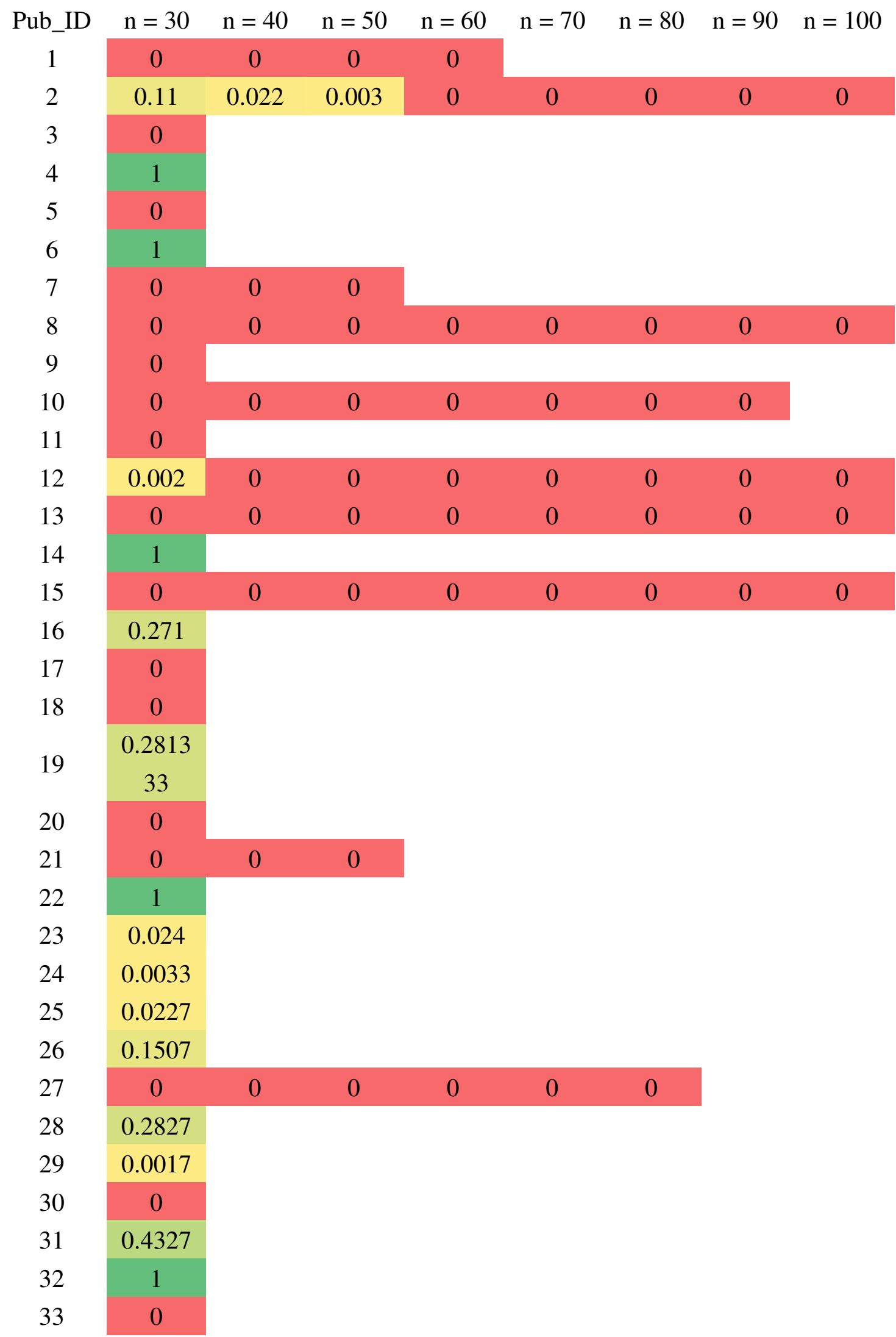




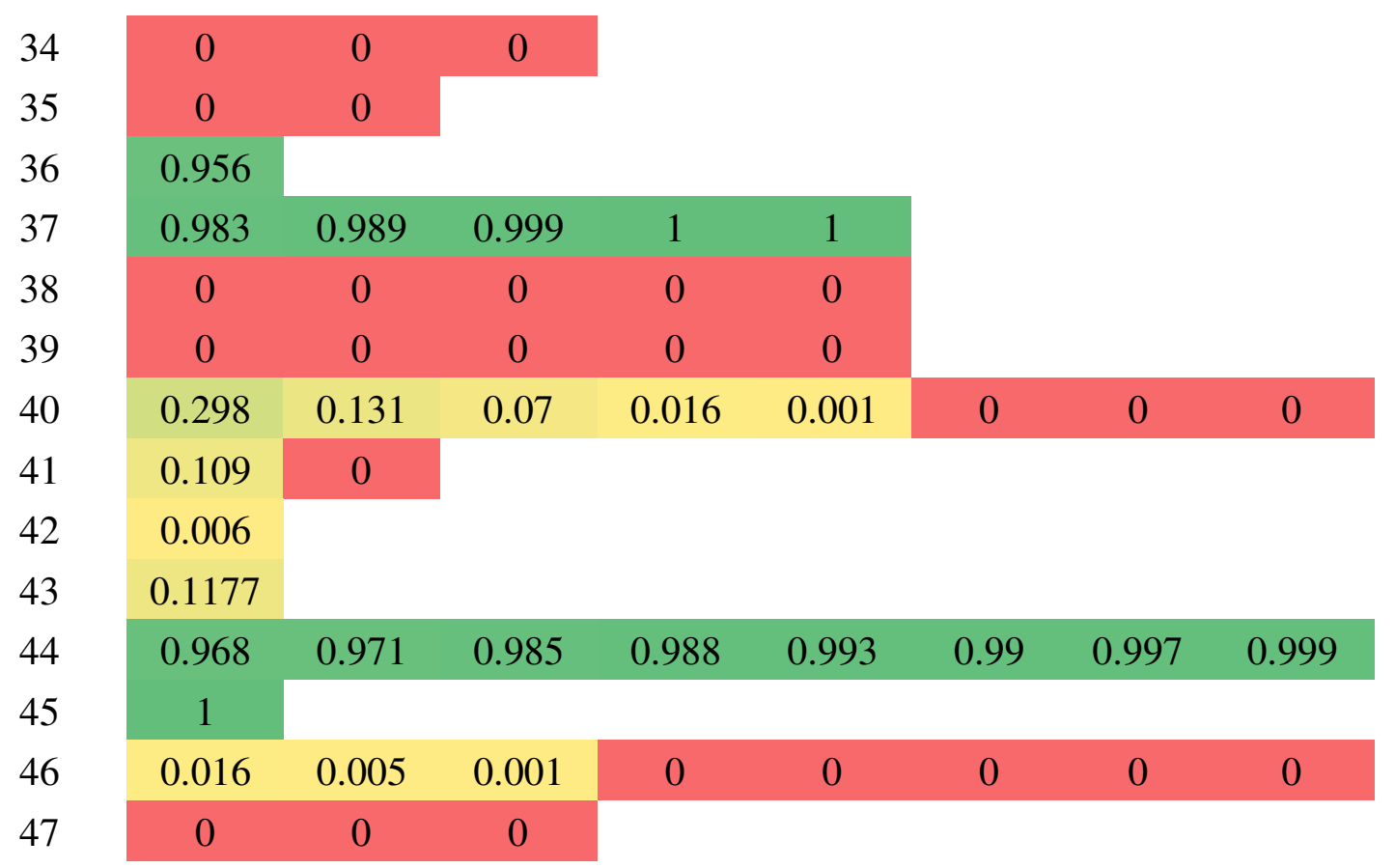

749

750 


\section{Figures}

(a)

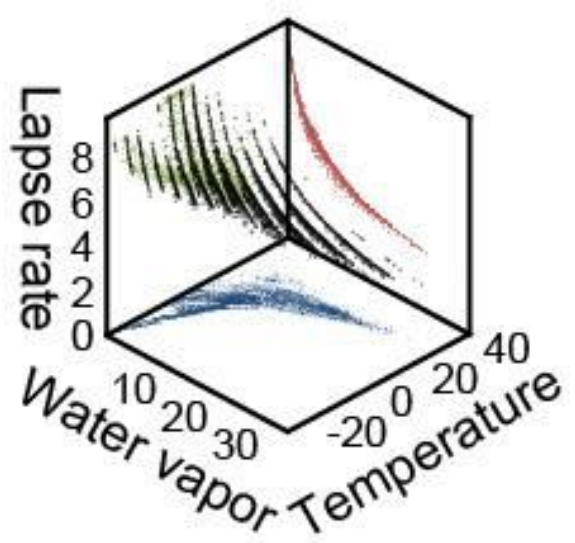

\section{(b) Mean temperature}

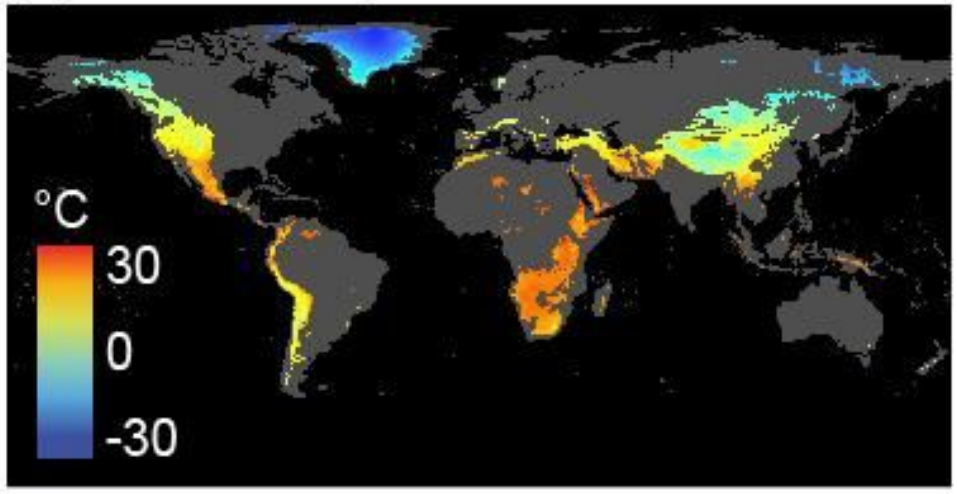

\section{(c) Mean water vapor}

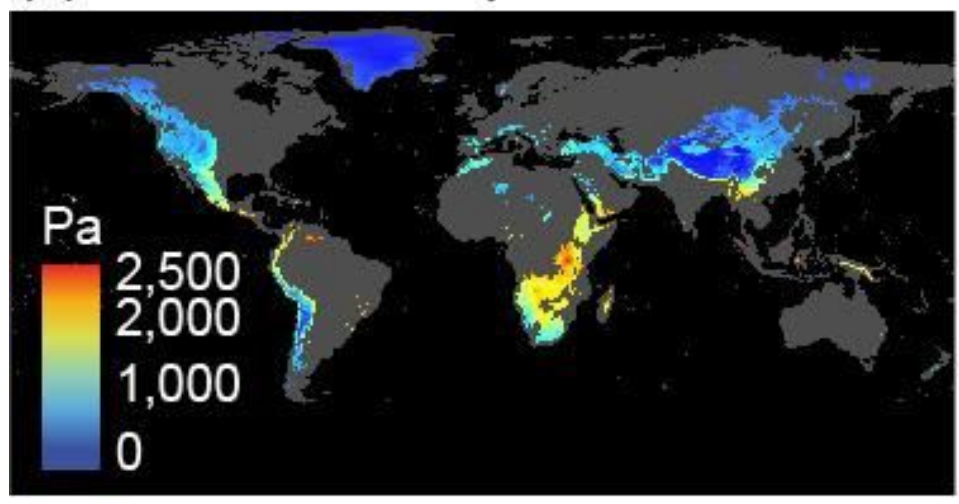

(d) Moist adiabatic lapse rate

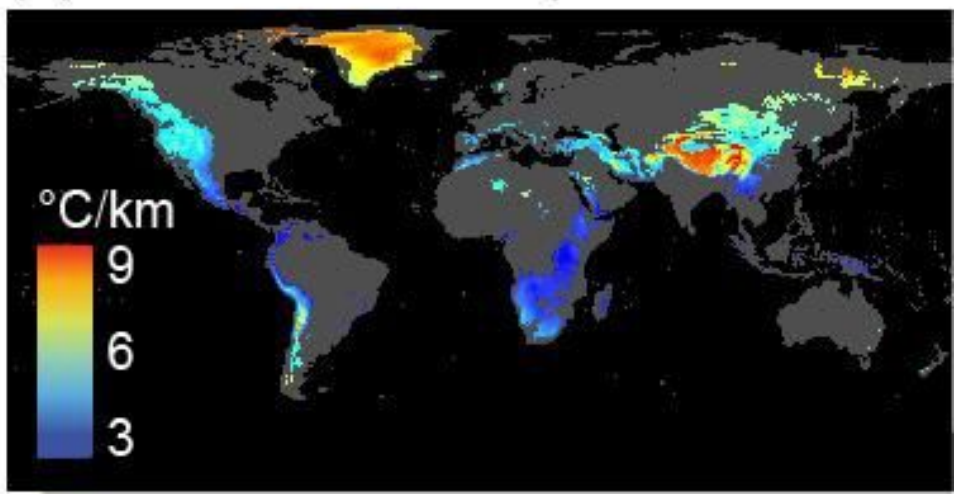

\section{Figure 1}

The foundation of moist adiabatic lapse rate for assessing climate velocity in global mountains. (a) The nonlinear effect of surface temperature and water vapor on lapse rate. The mean surface temperature (b) and water vapor (c) and derived mean moist adiabatic lapse rates (2011-2015) in global mountains (d). Note: The designations employed and the presentation of the material on this map do not imply the expression of any opinion whatsoever on the part of Research Square concerning the legal status of any country, territory, city or area or of its authorities, or concerning the delimitation of its frontiers or boundaries. This map has been provided by the authors. 
(a) Surface temperature change

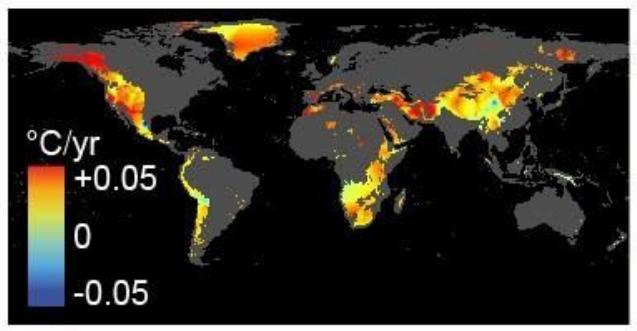

(b) Sea surface temp. change

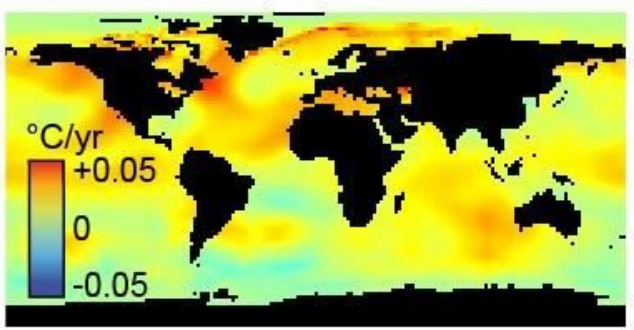

(c) Climate velocity

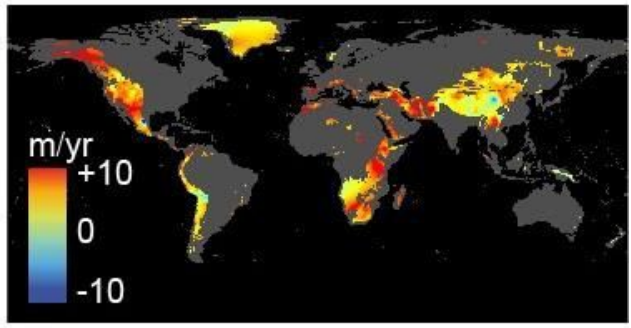

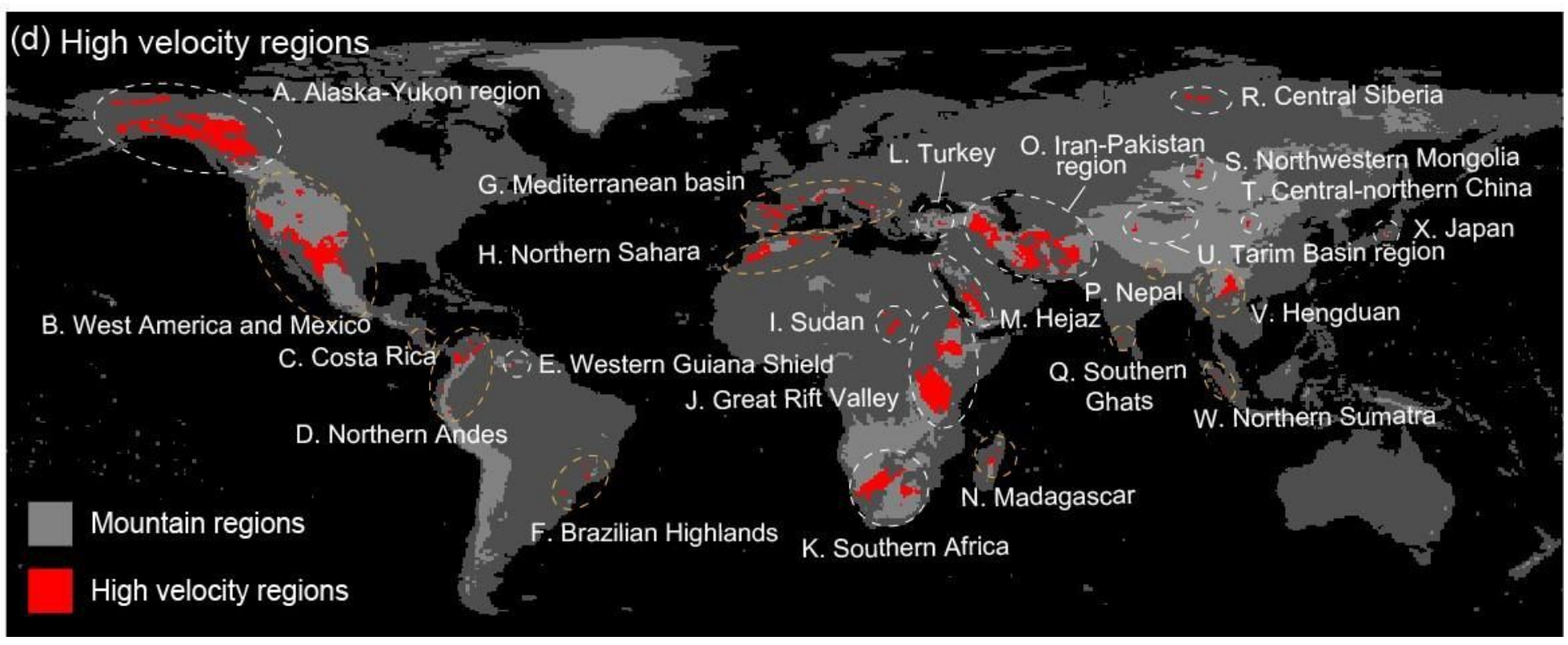

\section{Figure 2}

The velocity of climate change in global mountains from 1971 to 2015 . Terrestrial (a) and sea (b) surface temperature change (1971-1975 V.S. 2011-2015) and derived elevational climate velocities in mountains (c). (d) The high climate-velocity mountains are defined as where the isotherms have shifted more than one standard deviation of the global mean value (higher than $8.45 \mathrm{~m}$ yr-1). Note: The designations employed and the presentation of the material on this map do not imply the expression of any opinion whatsoever on the part of Research Square concerning the legal status of any country, territory, city or area or of its authorities, or concerning the delimitation of its frontiers or boundaries. This map has been provided by the authors. 

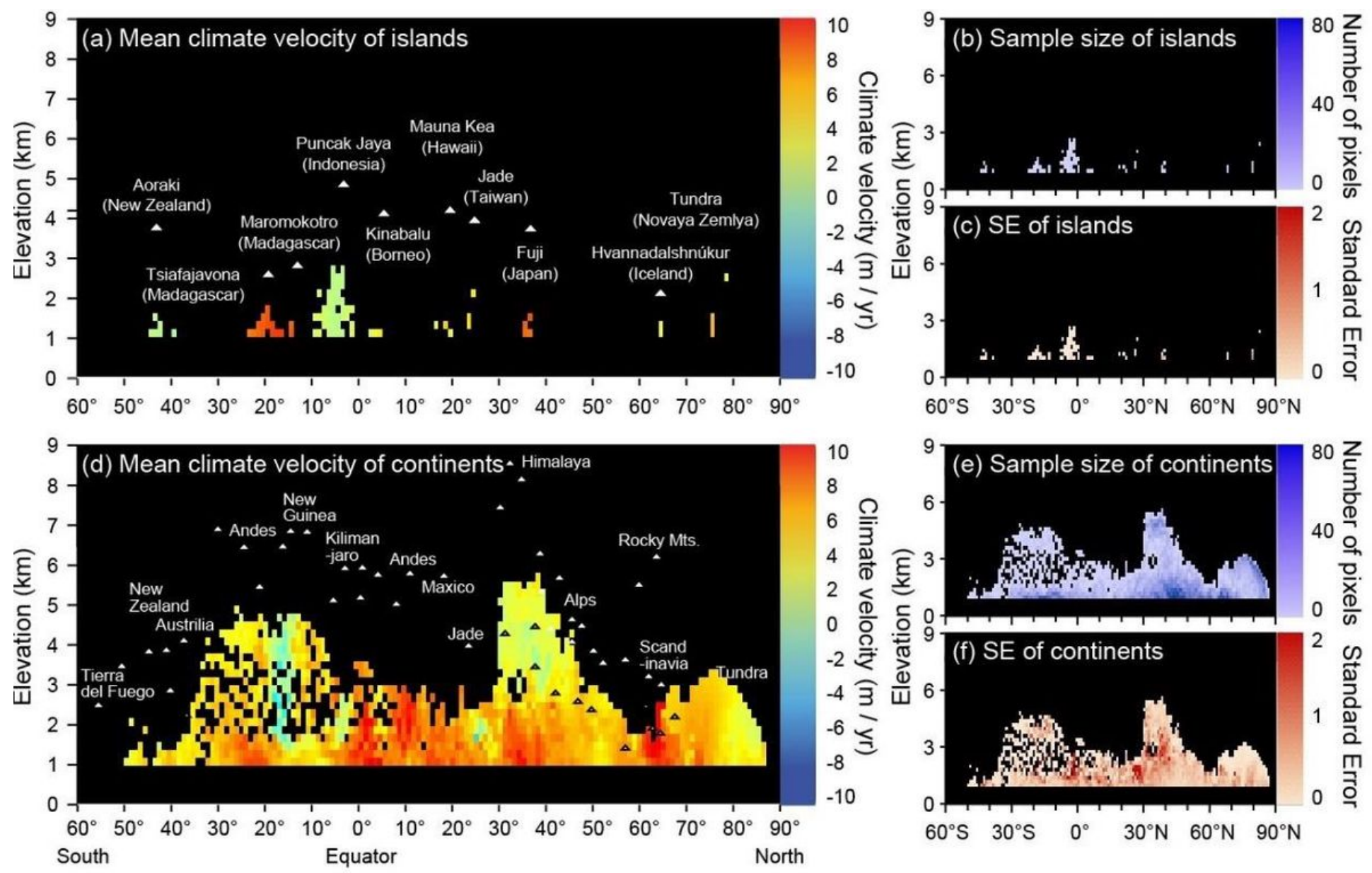

\section{Figure 3}

The velocity of climate change (1971-2015) in mountain islands (a, b, c) and along latitude-elevation gradients (d, e, f). Please see the Supplementary Method and Extended Data Fig. 3 for how to project a latitude-longitude map on a latitude-elevation map. Mountain summits are labeled for reference. Results that include the full 20th century (1901-2015) can be found in Supplementary Fig. 1 \& 2 . 


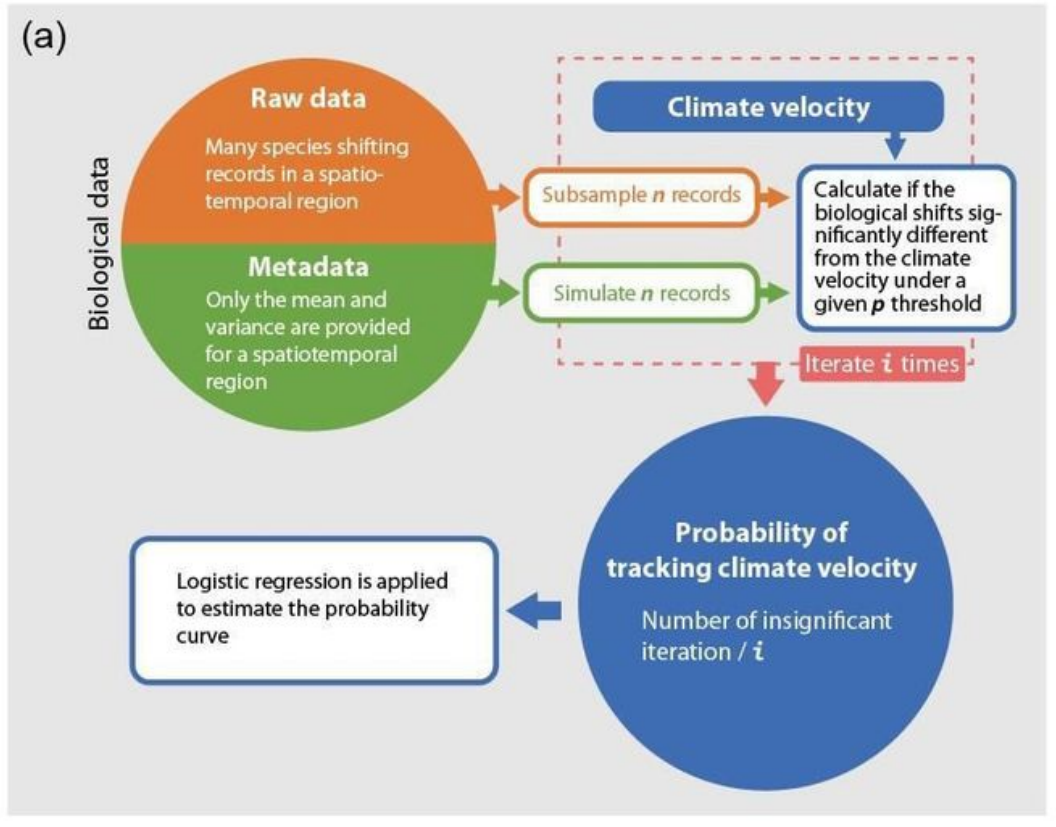

(c) $\boldsymbol{p}=0.05$

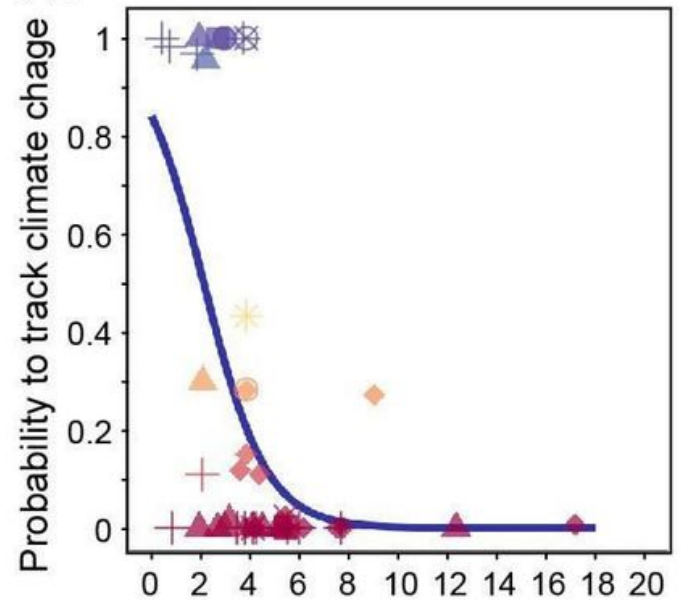

(d) $p=0.01$ (b)

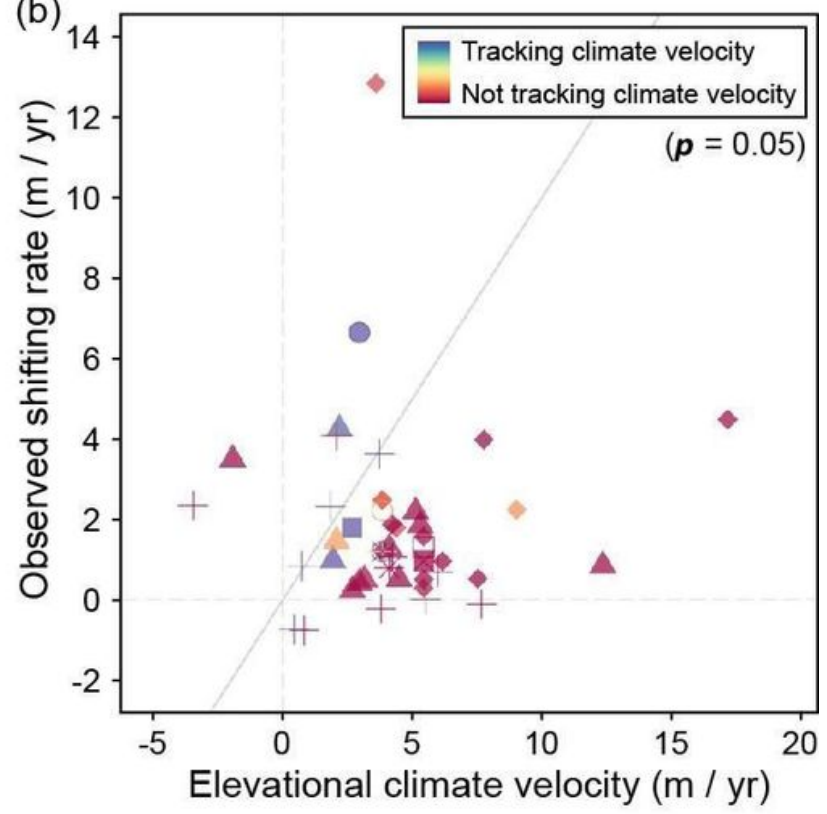

(e) $\boldsymbol{p}=0.001$

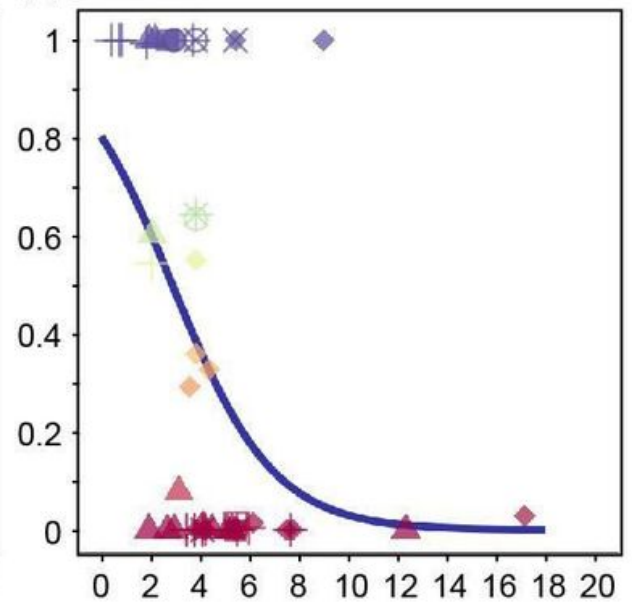

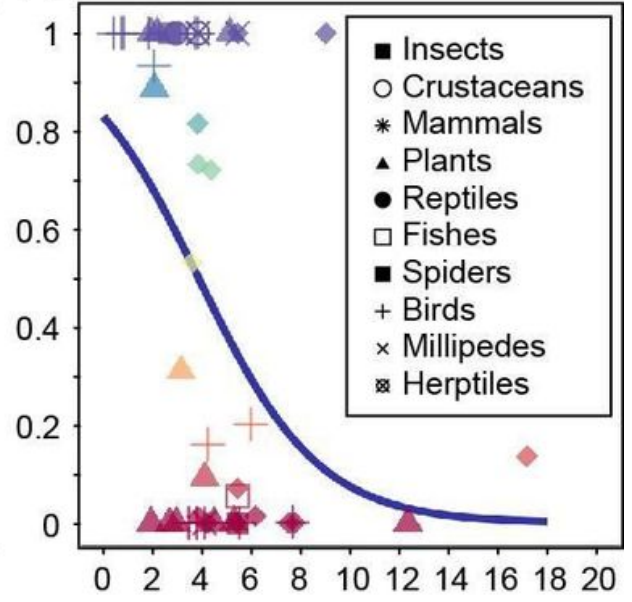

Nondirectional elevational climate velocity $(\mathrm{m} / \mathrm{yr})$

\section{Figure 4}

The probability of tracking climate velocities for mountain species. (a) The diagram summarizing how the probability of tracking climate velocities was calculated $(i=1000)(b)$ The diagonal diagram for observed range shifts for mountain species and corresponding climate velocities. Blue labels represent cases that species track climate successfully (color-coded under $p=0.05$ threshold). (c-e) The different probabilities of species tracking climate velocity under different $p$ thresholds. Only mean values are shown here. Panel c-e share the same color legend with panel b. For raw data points, please see Extended Data Fig. 9 for details. 